\title{
21. ONE MILLION YEAR RECORD OF SUMMER MONSOON WINDS AND CONTINENTAL ARIDITY FROM THE OWEN RIDGE (SITE 722), NORTHWEST ARABIAN SEA ${ }^{1}$
}

\author{
Steven C. Clemens ${ }^{2}$ and Warren L. Prell ${ }^{2}$
}

\begin{abstract}
The upper $38 \mathrm{~m}$ of Hole 722B sediments (Owen Ridge, northwest Arabian Sea) was sampled at $20 \mathrm{~cm}$ intervals and used to develop records of lithogenic percent, mass accumulation rate, and grain size spanning the past 1 m.y. Over this interval, the lithogenic component of Owen Ridge sediments can be used to infer variability in the strength of Arabian Sea summer monsoon winds (median grain size) and the aridity of surrounding dust source-areas (mass accumulation rate; MAR in $\mathrm{g} / \mathrm{cm}^{2} \cdot \mathrm{k} . \mathrm{y} .{ }^{-1}$ ). The lithogenic MAR has strong 100,41 , and $23 \mathrm{k} . \mathrm{y}$. cyclicities and is forced primarily by changes in source-area aridity associated with glacial-interglacial cycles. The lithogenic grain size, on the other hand, exhibits higher frequency variability ( $23 \mathrm{k} . \mathrm{y}$.) and is forced by the strength of summer monsoon winds which, in turn, are forced by the effective sensible heating of the Indian-Asian landmass and by the availability of latent heat from the Southern Hemisphere Indian Ocean. These forcing mechanisms combine to produce a wind-strength record which has no strong relationship to glacial-interglacial cycles. Discussion of the mechanisms responsible for production of primary Milankovitch cyclicities in lithogenic records from the Owen Ridge is presented elsewhere (Clemens and Prell, 1990). Here we examine the $1 \mathrm{~m}$.y. record from Hole 722B focusing on different aspects of the lithogenic components including an abrupt change in the monsoon wind-strength record at $500 \mathrm{k} . \mathrm{y}$., core-to-core reproducibility, comparison with magnetic susceptibility, coherency with a wind-strength record from the Pacific Ocean, and combination frequencies in the wind-strength record.

The Hole 722B lithogenic grain-size record shows an abrupt change at $500 \mathrm{k} . \mathrm{y}$. possibly indicating decreased monsoon wind-strength over the interval from $500 \mathrm{k} . y$. to present. The grain-size decrease appears to be coincident with a loss of spectral power near the 41 k.y. periodicity. However, the grain-size decrease is not paralleled in the Globigerina bulloides upwelling record, an independent record of summer monsoon wind-strength (Prell, this volume). These observations leave us with competing hypotheses possibly involving: (1) a decrease in the sensitivity of monsoon windstrength to obliquity forcing, (2) decoupling of the grain size and $G$. bulloides records via a decoupling of the nutrient supply from wind-driven upwelling, and/or (3) a change in dust source-area or the patterns of dust transporting winds.

Comparison of the lithogenic grain size and weight percent records from Hole 722B with those from a nearby core shows that the major and most minor events are well replicated. These close matches establish our confidence in the lithogenic extraction techniques and measurements. Further, reproducibility on a core-to-core scale indicates that the eolian depositional signal is regionally strong, coherent, and well preserved.

The lithogenic weight percent and magnetic susceptibility are extremely well correlated in both the time and frequency domains. From this we infer that the magnetically susceptible component of Owen Ridge sediments is of terrestrial origin and transported to the Owen Ridge via summer monsoon winds. Because of the high correlation with the lithogenic percent record, the magnetic susceptibility record can be cast in terms of lithogenic MAR and used as a high resolution proxy for continental aridity.

In addition to primary Milankovitch periodicities, the Hole 722B grain-size record exhibits periodicity at $52 \mathrm{k} . \mathrm{y}$. and at 29 k.y. Both periodicities are also found in the grain-size record from piston core RC11-210 in the equatorial Pacific Ocean. Comparison of the two grain-size records shows significant coherence and zero phase relationships over both the 52 and 29 k.y. periodicities suggesting that the strengths of the Indian Ocean monsoon and the Pacific southeasterly trade winds share common forcing mechanisms.

Two possible origins for the 52 and 29 k.y. periodicities in the Hole 722B wind-strength record are (1) direct Milankovitch forcing ( 54 and 29 k.y. components of obliquity) and (2) combination periodicities resulting from nonlinear interactions within the climate system. We find that the 52 and $29 \mathrm{k} . y$. periodicities show stronger coherency with crossproducts of eccentricity and obliquity ( $29 \mathrm{k} . \mathrm{y}$.) and precession and obliquity ( $52 \mathrm{k} . \mathrm{y}$.) than with direct obliquity forcing. Our working hypothesis attributes these periodicities to nonlinear interaction between external insolation forcing and internal climatic feedback mechanisms involving an interdependence of continental snow/ice-mass (albedo) and the hydrological cycle (latent heat availability).
\end{abstract}

\section{INTRODUCTION}

The modern Arabian Sea summer monsoon has two dominant driving mechanisms: (1) differential heating of the southern Asia land-mass relative to the Indian Ocean, resulting in a northeast-southwest low level pressure gradient which drives southwest monsoon winds and (2) direct heating of the tropo-

\footnotetext{
${ }^{1}$ Prell, W. L., Niitsuma, N., et al., 1991. Proc. ODP, Sci. Results, 117: College Station, TX (Ocean Drilling Program).

2 Department of Geological Sciences, Brown University, Providence, RI 02912 1846, U.S.A.
}

sphere via latent heat collected over the Indian Ocean, transported north via monsoon winds, and released through precipitation over the Indian Ocean and precipitated in the form of rain over the Indian-Asian landmass (Webster, 1987). The release of latent heat directly into the troposphere increases the low pressure system over the Indian-Asia landmass strengthening the northeast-southwest pressure gradients established by differential sensible heating. Variability in the strength of these two mechanisms may also be partially responsible for variations in monsoon wind-strength over the geological past (Clemens and Prell, 1990).

Strong winds and the proximity of arid source-areas result in a large flux of desert dust from the continents to the northwest 
Arabian Sea during the summer monsoon season (McDonald, 1938; Prospero, 1981; Ackerman and Cox, 1982; Prodi et al., 1983; Chester et al., 1985; Middleton, 1986; Savoie et al., 1987; Ackerman and Cox, 1988; Sirocko and Sarnthein, 1989). Thus, one method of monitoring changes in this system over the geological past is to examine the lithogenic grain-size and mass accumulation rate (MAR in $\mathrm{g} / \mathrm{cm}^{2} \cdot \mathrm{k.y.}^{-1}$ ) of Arabian Sea sediments.

\section{Background and Previous Work}

Recent monsoon-related research has focused on modern seasonal variations in the flux of eolian material from the surrounding deserts to the Arabian Sea. Meteorological observations of historical dust storm frequency indicate that the primary season of dust transport is during the southwest monsoon months of June, July, and August (McDonald, 1938; Prospero, 1981; Middleton, 1986). These observations are consistent with satellite studies indicating that $90 \%$ of the atmospheric transcoastal dust transport takes place in June, July, and August (Sirocko and Sarnthein, 1989). Results from sediment trap studies indicate that, in the western Arabian Sea, $80 \%$ of the lithogenic flux to the seafloor occurs during the southwest monsoon months of June through September indicating an instantaneous transfer of the atmospheric signal into the sedimentary record (Nair et al., 1989). During the same months, lithogenic flux to the eastern Arabian Sea is $70 \%$ greater even though atmospheric dust flux to this region is negligible. Such observations indicate that the dominant lithogenic input to the western Arabian Sea is eolian in origin and that, in contrast, lithogenic input to the eastern Arabian Sea consists of sediment from Indus river runoff; $80 \%$ of the yearly runoff occurs during the southwest monsoon months and is transported to the southeast by oceanic surface currents (Milliman et al., 1984; Nair et al., 1989).

Lithogenic grains found in the northwest Arabian Sea (median diameter up to $18.5 \mu \mathrm{m}$ ) can be transported on the order of a few thousand kilometers given atmospheric characteristics found in typical cyclonic storms and frontal systems (Tsoar and Pye, 1987). These estimates of transport distance are consistent with satellite studies which indicate that major source-areas for dust during the modern summer monsoon include the Somali and Arabian Peninsulas and that the transporting winds include the southwest monsoon winds as well as northwest winds off Arabia (Grigoryev et al., 1971; Ackerman and Cox, 1982; Middleton, 1986; Ackerman and Cox, 1988; Sirocko and Sarnthein, 1989).

In summary, modern observations indicate that lithogenic material deposited in the northwest Arabian Sea is dominantly eolian and is transported almost exclusively during the summer monsoon season. Such observations provide a solid framework for the study of lithogenic material over geological time scales using cores recovered from the Owen Ridge (Fig. 1).

The Owen Ridge, located $350 \mathrm{~km}$ off the coast of the Arabian Peninsula, is well suited to receiving and preserving the eolian signal over the past several million years. The ridge roughly parallels the coast of Oman, rising $1500 \mathrm{~m}$ above the Oman Basin to the northwest and $2000 \mathrm{~m}$ above the Indus Fan to the southeast (Fig. 1). Previous work on Owen Ridge piston-core RC27-61 (Clemens and Prell, 1990) has shown that over the past 370 k.y: (1) the lithogenic component of Owen Ridge sediments is of eolian origin; (2) the lithogenic mass accumulation rate (MAR) is an effective proxy indicator of source-area aridity (increased aridity during glacial periods results in decreased vegetation cover and increased soil deflation); (3) the median grain size of the lithogenic component is an effective proxy indicator of summer monsoon wind-strength (increased wind-strength resulting in the transport of larger grains); (4) both the MAR and
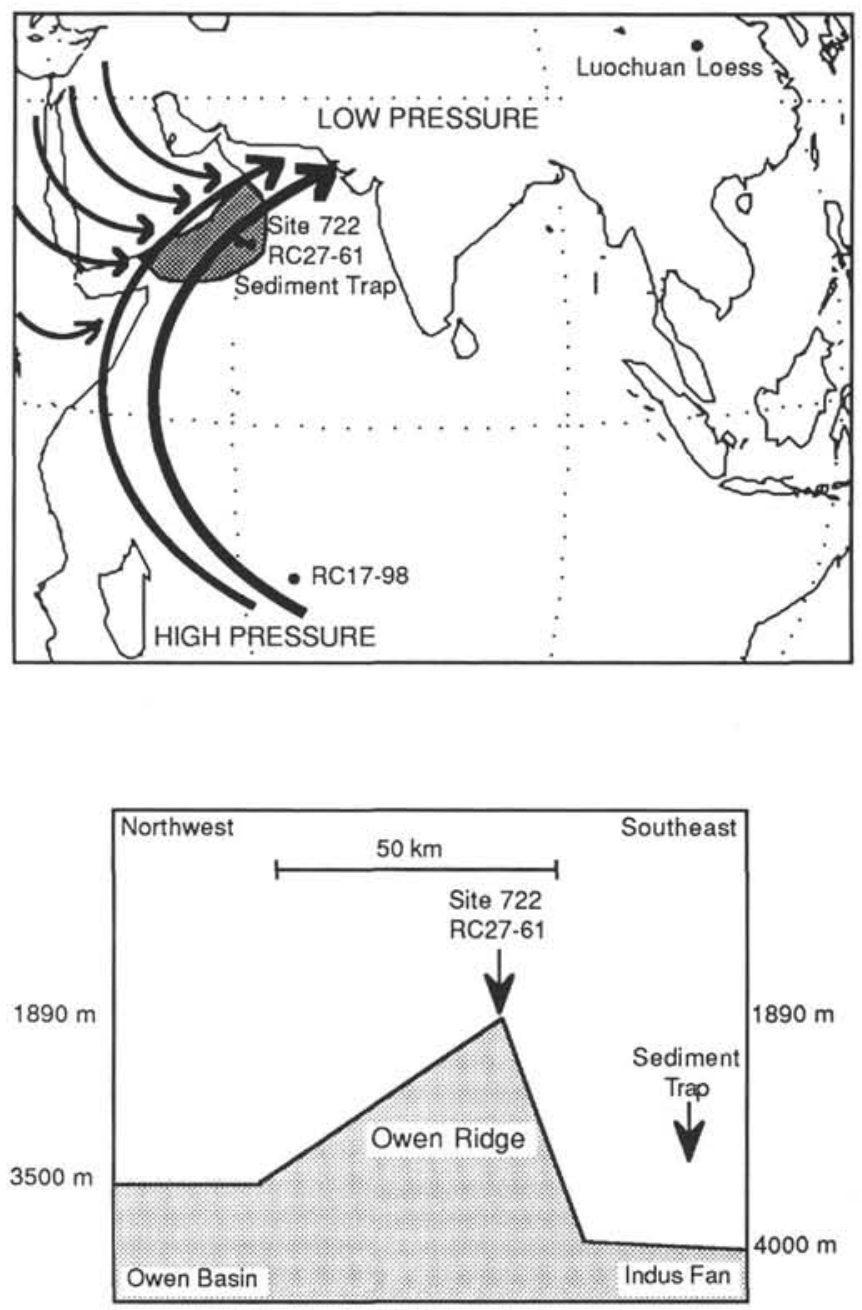

Figure 1. Site location map. ODP Site $722\left(16^{\circ} 37.31^{\prime} \mathrm{N}, 59^{\circ} 47.76^{\prime} \mathrm{E}\right.$, $2028 \mathrm{mbsl})$, piston core RC27-61 (16 $\left.{ }^{\circ} 37.5^{\prime} \mathrm{N}, 59^{\circ} 51.7^{\prime} \mathrm{E}, 1890 \mathrm{mbsl}\right)$, piston core $\mathrm{RC} 17-98\left(13^{\circ} 13^{\prime} \mathrm{S}, 65^{\circ} 37^{\prime} \mathrm{E} ; 3409 \mathrm{mbsl}\right)$, sediment trap site $\left(16^{\circ} 19^{\prime} \mathrm{N}, 60^{\circ} 28^{\prime} \mathrm{E}, 3000 \mathrm{~m}\right.$ water depth; Nair et al., 1989$)$, and a record of loess from central China (Kukla et al., 1988). The arrows represent the directions of dust-transporting summer winds. The lower figure is a schematic profile of the Owen Ridge, perpendicular to the ridge axis, showing the location of Site 722, core RC27-61, and the sediment trap ( $\sim 70 \mathrm{~km}$ east-southeast of RC27-61 and Site 722).

grain size are consistent with independent proxy indicators of aridity and southwest monsoon wind-strength; (5) both the MAR and grain size are coherent with precessional insolation (referenced to 21 June) and with one another, but exhibit a phase difference of 8 k.y. (maximum grain size lags maximum insolation by 9 k.y. while maximum MAR leads maximum insolation by 6 k.y.); (6) the aridity lead can be attributed to climatic changes associated with glacial-interglacial cycles; and (7) the windstrength lag can be accounted for by interaction between insolation and global/local snow and ice volume changes which alter the effective sensible heating (albedo) of the Asian continent and by the availability of latent heat supplied by the Southern Hemisphere Indian Ocean. The phase relationships discussed above are summarized in Figure 2. Work thus far indicates that phase relationships from Hole $722 \mathrm{~B}$ sediments, spanning the last $1 \mathrm{~m} . \mathrm{y}$., are consistent with those derived from Core RC2761 sediments $(0-370$ k.y.). 


\section{-PRECESSION (23 ky)}

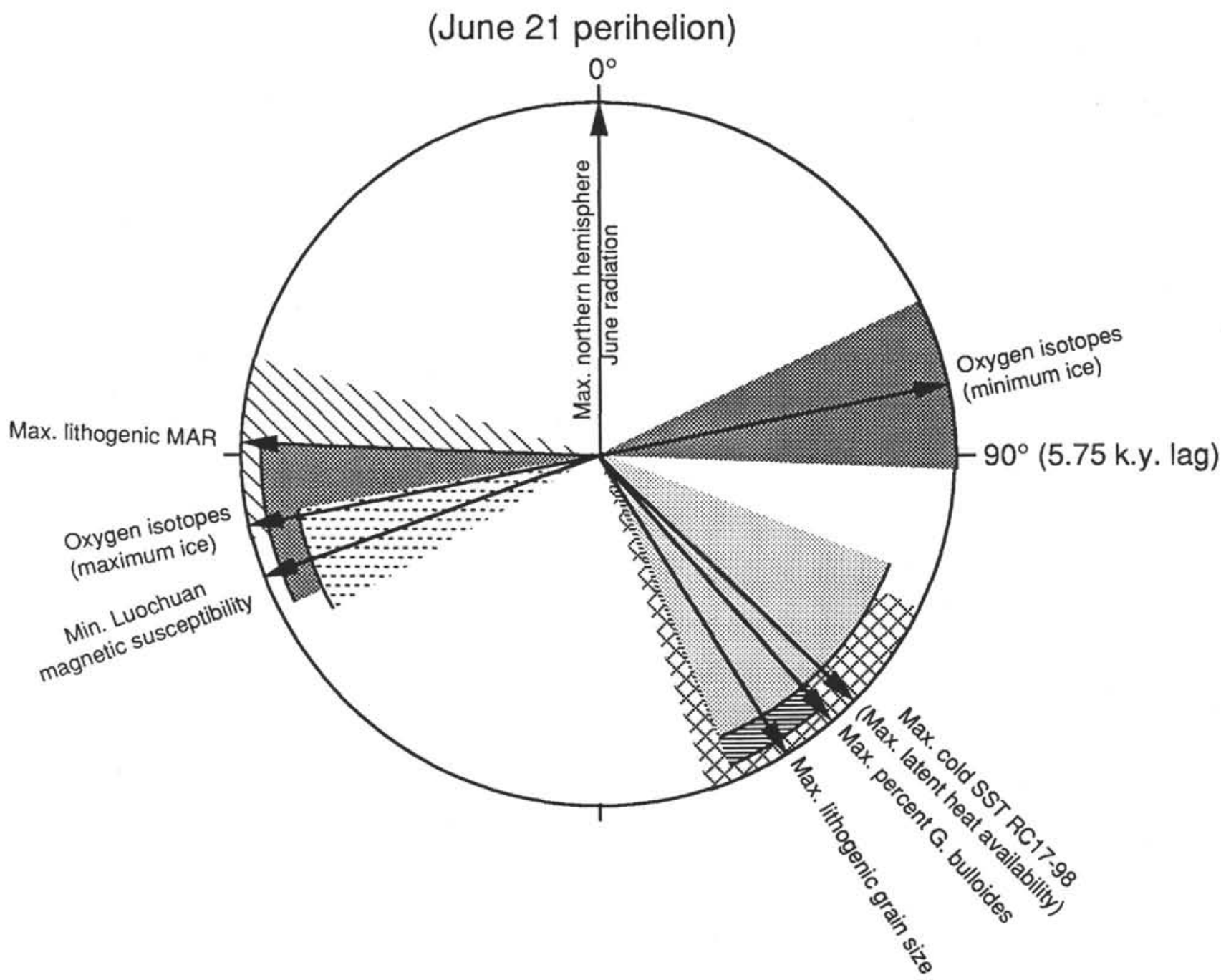

Figure 2. Phase wheel for climatic indices. A phase wheel is a diagram for keeping track of phase relationships between climatic indices and external climatic forcing mechanisms (precession in this case). Zero phase is located at the top of the circle. The phase difference between minimum precession of the Earth's orbit (maximum precessional insolation) and a given climatic record is plotted as a vector whose angle is measured clockwise $(+$, lagging) or counterclockwise $(-$, leading) from the zero point. The shaded area centered on a given vector represents the error associated with the phase estimate. With respect to the precession cycle, minimum ice volume, as indicated by oxygen isotopes, lags maximum insolation by $5 \mathrm{k} . \mathrm{y} .\left(79^{\circ}\right)$. Maximum monsoon wind-strength follows about $4 \mathrm{k}$.y. later as indicated both by maximum percent $G$. bulloides (summer monsoon upwelling index) and maximum lithogenic grain size (summer monsoon wind-strength index). The grain-size record is in phase with both the $G$. bulloides upwelling index and the RCl7-98 SST record (latent heat index). Finally, maximum continental aridity follows about 9 k.y. later as indicated by maximum lithogenic MAR (dust-source-area aridity index) and the Luochuan magnetic susceptibility record (central China aridity index; Kukla et al., 1988) both of which are in phase with maximum ice volume as indicated by oxygen isotopes.

\section{Objectives}

The objectives of this study are as follows: (1) to measure the weight percent, MAR, and grain size of the lithogenic component from the top $38 \mathrm{~m}$ of Hole $722 \mathrm{~B}$, thus extending the length of the Owen Ridge eolian records from 370 k.y. (RC27-61) to 955 k.y.; (2) to demonstrate the reproducibility of the extraction procedure and grain-size measurements for two different cores from the same region; (3) to evaluate the paleoclimatic significance of the magnetic susceptibility record by comparison to the lithogenic records; (4) to demonstrate for the first time interocean coherence for wind-strength records; and (5) to examine the nonlinear frequencies (combination frequencies) present in the wind-strength record.

\section{METHODS}

Sediments used in this study are from lithologic unit I (Shipboard Scientific Party, 1989), and are composed of alternating light and dark layers of foraminifer-bearing nannofossil ooze and marly nannofossil ooze. The upper $38 \mathrm{~m}$ of Hole 722B (100\% recovery) was sampled at $20 \mathrm{~cm}$ intervals. The resulting record spans the past $1 \mathrm{~m}$.y. before present. The $20 \mathrm{~cm}$ sampling interval, combined with an average sedimentation rate of 4.6 $\mathrm{cm} / \mathrm{k}$.y. yields $4.3 \mathrm{k}$.y. resolution.

The lithogenic component was isolated by a wet chemical extraction procedure, allowing measurement of the lithogenic weight percent, MAR, and median grain-size diameter ( $\mu \mathrm{m}$; volumetric distribution). A detailed description of the extraction 
procedure and the laboratory techniques used in grain-size measurements is published elsewhere (Clemens and Prell, 1990). Precision of the analyses for Hole 722B samples, based on a set of 19 replicates, is $\pm 0.2 \mu \mathrm{m}$ for the grain-size measurements and $\pm 0.5 \mathrm{wt} \%$ for the lithogenic percent measurement (mean half-range).

The age model for the upper 780 k.y. of Hole 722B was developed by correlation of the oxygen isotope record from Hole 722B to the SPECMAP stacked oxygen isotope record (Imbrie et al., 1984). The age model for the portion 780 to 954 k.y. was developed by correlation of the Hole 722B oxygen isotope record to the Atlantic Site 607 oxygen isotope record (Ruddiman et al., 1989) followed by tuning to orbital obliquity. The differences between the record tuned to obliquity and that correlated directly to the Site 607 record were negligible. The age model for the top $40 \mathrm{~m}$ of Hole $722 \mathrm{~B}$ is presented in Table 1 (see also Prell, this volume).

MAR's were calculated by multiplying the linear sedimentation rates (LSR; cm/k.y.) derived from the age model (Table 1) with the dry bulk density $\left(\mathrm{g} / \mathrm{cm}^{3}\right)$ and the lithogenic percent (Table 2). Dry bulk density values for samples used in this study were derived from the GRAPE wet bulk density log (Busch, this volume) using the following procedure. A spline curve was fit to the GRAPE wet bulk density (GWBD) record and sampled at the depths for which discrete dry bulk density (DDBD) values were measured aboard ship. From these data, a linear regression equation was derived allowing estimate of DDBD values from the GWBD record $(\mathrm{DDBD}=-1.2664+1.3481(\mathrm{GWBD}) ; \mathrm{R}$ $=0.84, \mathrm{n}=30\}$.

For the purposes of spectral analysis, the records have been interpolated at 2 k.y. intervals. Evaluation of the temporal resolution between adjacent samples indicates that the lithogenic record will provide reliable estimates in the frequency domain over all the primary Milankovitch frequency bands $(400,100$, 41,23 , and 19 k.y.). All analyses were carried out using standard techniques (Jenkins and Watts, 1968; Imbrie et. al., 1989).

Below we present and discuss our lithogenic records and their relationship to several somewhat distinct topics. We discuss the lithogenic records in relation to: (1) dust source-area aridity and summer monsoon wind-strength over the past million years; (2) intercore reproducibility of the lithogenic records; (3) magnetic susceptibility; and (4) combination frequencies in the Hole 722B wind-strength record and coherence with eolian records from the Pacific Ocean. We present each topic and discussion separately.

\section{LITHOGENIC COMPONENT (HOLE 722B)}

\section{Lithogenic Time-Series}

Records of the lithogenic percent, MAR (proxy for sourcearea aridity), and the median grain size (proxy for summer monsoon wind-strength) are plotted in Figure 3 (Table 2). The lithogenic component accounts for $14 \%-51 \%$ of the sediment by weight; the remainder is composed of biogenic carbonate $(52 \%-$ $83 \%)$ and small amounts of biogenic opal $(0 \%-5 \%)$. The lithogenic MAR ranges from 0.25 to $4.2 \mathrm{~g}\left(\mathrm{~cm}^{2} \cdot \mathrm{k} . \mathrm{y} \text {. }\right)^{-1}$ and is positively correlated with the lithogenic percent. The lithogenic grain size ranges from 12.4 to $18.3 \mu \mathrm{m}$ and varies with a higher frequency than the lithogenic percent and MAR records. Unlike the lithogenic percent and MAR records, the grain-size record shows a distinct change in amplitude at $500 \mathrm{ka}$. Mean grain size over the 954-500 k.y. interval is $15.2 \pm 1.22 \mu \mathrm{m}$, decreasing to $14.5 \pm 0.82 \mu \mathrm{m}$ over the interval from 500 k.y. to 6 k.y. (Fig. 3). This change does not appear to be coincident with any distinct changes in the magnetic susceptibility, isotopes, lithogenic percent, or lithogenic MAR records.
Table 1. Oxygen isotopic data and age model for Hole 722B (0-40 m). Oxygen isotopic value (PDB; G. sacculifer). The ages are assigned by linear interpolation between age picks $(\dagger)$ derived by correlation to the SPECMAP stacked oxygen isotope record and the Site 607 oxygen isotope record (Ruddiman et al., 989).

\begin{tabular}{|c|c|c|c|}
\hline $\begin{array}{l}\text { Depth } \\
\text { in core } \\
\text { (m) }\end{array}$ & $\begin{array}{c}\text { Age } \\
\text { (k.y.B.P.) }\end{array}$ & $\begin{array}{c}\text { Stages } \\
\text { (Imbrie et al., } \\
1984)\end{array}$ & $\begin{array}{c}\text { Oxygen } \\
\text { isotopes } \\
\text { (PDB) }\end{array}$ \\
\hline 0.01 & $6.00 \dagger$ & 1.10 & -1.47 \\
\hline 0.21 & 8.36 & & -0.97 \\
\hline 0.41 & 10.72 & & -0.23 \\
\hline 0.61 & 13.08 & & 0.17 \\
\hline 0.81 & 15.44 & & 0.17 \\
\hline 1.01 & $17.80 \dagger$ & 2.22 & 0.43 \\
\hline 1.21 & 21.90 & & 0.20 \\
\hline 1.41 & 26.01 & & 0.49 \\
\hline 1.61 & 30.11 & & 0.23 \\
\hline 1.81 & 34.22 & & -0.06 \\
\hline 2.01 & 38.32 & & -0.08 \\
\hline 2.21 & 42.43 & & -0.01 \\
\hline 2.41 & 46.53 & & -0.22 \\
\hline 2.61 & 50.63 & & -0.44 \\
\hline 2.81 & 54.74 & & 0.03 \\
\hline 3.01 & 58.84 & & -0.30 \\
\hline 3.21 & 62.95 & & 0.19 \\
\hline 3.31 & $65.00 \dagger$ & 4.20 & \\
\hline 3.41 & 68.00 & & 0.15 \\
\hline 3.61 & 74.00 & & -0.37 \\
\hline 3.81 & $80.00 \dagger$ & 5.10 & -0.53 \\
\hline 4.01 & 89.50 & & -0.41 \\
\hline 4.21 & $99.00 \dagger$ & 5.30 & -0.99 \\
\hline 4.41 & 108.20 & & -0.51 \\
\hline 4.61 & 117.40 & & -1.16 \\
\hline 4.71 & $122.00 \dagger$ & 5.50 & \\
\hline 4.81 & 123.60 & & -1.11 \\
\hline 5.01 & 126.70 & & -0.20 \\
\hline 5.21 & 129.80 & & 0.26 \\
\hline 5.54 & $135.00^{\dagger}$ & 6.20 & 0.43 \\
\hline 5.71 & 138.00 & & 0.05 \\
\hline 5.91 & 141.40 & & 0.16 \\
\hline 6.11 & 144.90 & & 0.20 \\
\hline 6.31 & 148.40 & & -0.01 \\
\hline 6.51 & 151.90 & & 0.15 \\
\hline 6.71 & 155.30 & & -0.12 \\
\hline 6.91 & 158.80 & & 0.02 \\
\hline 7.11 & 162.30 & & 0.02 \\
\hline 7.31 & 165.80 & & -0.27 \\
\hline 7.51 & 169.30 & & -0.36 \\
\hline 7.61 & $171.00 \dagger$ & 6.50 & \\
\hline 7.71 & 173.40 & & -0.40 \\
\hline 7.91 & 178.20 & & -0.14 \\
\hline 8.11 & $183.00 \dagger$ & 6.60 & 0.02 \\
\hline 8.31 & 191.90 & & -0.79 \\
\hline 8.51 & 200.70 & & -0.82 \\
\hline 8.71 & 209.60 & & -1.17 \\
\hline 8.91 & $218.40 \dagger$ & & -0.72 \\
\hline 9.11 & 222.30 & & -0.83 \\
\hline 9.31 & 226.20 & & -0.27 \\
\hline 9.51 & 230.20 & & -0.48 \\
\hline 9.71 & 234.10 & & -0.36 \\
\hline 9.91 & $238.00+$ & 7.50 & -0.79 \\
\hline 10.11 & 241.70 & & -0.37 \\
\hline 10.31 & 245.30 & & -0.11 \\
\hline 10.51 & $249.00 \dagger$ & 8.20 & -0.01 \\
\hline 10.71 & 252.30 & & -0.03 \\
\hline 10.91 & 255.70 & & -0.08 \\
\hline 11.11 & 259.00 & & 0.07 \\
\hline 11.31 & 262.30 & & 0.07 \\
\hline 11.51 & 265.70 & & 0.31 \\
\hline 11.71 & $269.00 \dagger$ & 8.40 & 0.34 \\
\hline 11.91 & 278.00 & & -0.29 \\
\hline 12.11 & $287.00 \dagger$ & 8.50 & -0.57 \\
\hline 12.31 & 293.00 & & -0.29 \\
\hline 12.51 & $299.00 \dagger$ & 8.60 & -0.17 \\
\hline 12.71 & 307.00 & & -0.39 \\
\hline 12.91 & 315.00 & & -0.77 \\
\hline
\end{tabular}


Table 1 (continued).

\begin{tabular}{|c|c|c|c|}
\hline $\begin{array}{l}\text { Depth } \\
\text { in core } \\
(\mathrm{m})\end{array}$ & $\begin{array}{c}\text { Age } \\
\text { (k.y.B.P.) }\end{array}$ & $\begin{array}{c}\text { Stages } \\
\text { (Imbrie et al., } \\
\text { 1984) }\end{array}$ & $\begin{array}{c}\text { Oxygen } \\
\text { isotopes } \\
\text { (PDB) }\end{array}$ \\
\hline 13.11 & 323.00 & & -0.68 \\
\hline 13.31 & $331.00 \dagger$ & 9.30 & -1.18 \\
\hline 13.51 & 333.90 & & -0.75 \\
\hline 13.71 & 336.70 & & -0.35 \\
\hline 13.91 & 339.60 & & 0.11 \\
\hline 14.01 & $341.00+$ & 10.20 & \\
\hline 14.11 & 343.30 & & 0.36 \\
\hline 14.31 & 347.80 & & 0.06 \\
\hline 14.51 & 352.30 & & -0.05 \\
\hline 14.71 & 356.90 & & -0.27 \\
\hline 15.11 & 365.90 & & -0.39 \\
\hline 15.31 & 370.50 & & -0.32 \\
\hline 15.51 & $375.00 \dagger$ & 11.20 & -0.22 \\
\hline 15.71 & 381.00 & & -0.36 \\
\hline 15.91 & 387.00 & & -0.78 \\
\hline 16.11 & 393.00 & & -0.52 \\
\hline 16.31 & 399.00 & & -1.21 \\
\hline 16.51 & $405.00 \dagger$ & 11.30 & -1.31 \\
\hline 16.71 & $423.00 \dagger$ & 12.00 & -0.40 \\
\hline 16.91 & 426.70 & & -0.01 \\
\hline 17.11 & 430.30 & & 0.41 \\
\hline 17.31 & $434.00 \dagger$ & 12.20 & 0.46 \\
\hline 17.51 & 438.50 & & 0.31 \\
\hline 17.71 & 443.00 & & 0.43 \\
\hline 17.91 & 447.50 & & 0.32 \\
\hline 18.11 & 452.00 & & 0.17 \\
\hline 18.31 & 456.50 & & -0.03 \\
\hline 18.51 & $461.00 \dagger$ & 12.33 & -0.12 \\
\hline 18.71 & 466.00 & & -0.02 \\
\hline 18.91 & $471.00 \dagger$ & 12.40 & 0.09 \\
\hline 19.11 & 477.70 & & 0.03 \\
\hline 19.31 & 484.30 & & -0.21 \\
\hline 19.51 & $491.00 \dagger$ & 13.12 & -0.33 \\
\hline 19.71 & 502.00 & & -0.22 \\
\hline 19.91 & $513.00 \dagger$ & 13.20 & -0.16 \\
\hline 20.11 & 517.40 & & -0.37 \\
\hline 20.31 & 521.80 & & -0.66 \\
\hline 20.41 & $524.00 \dagger$ & 14.00 & \\
\hline 20.51 & 528.70 & & -0.68 \\
\hline 20.71 & $538.00 \dagger$ & 14.20 & -0.26 \\
\hline 20.91 & $552.00 \dagger$ & 14.30 & -0.53 \\
\hline 21.11 & $563.00 \dagger$ & 14.40 & -0.34 \\
\hline 21.31 & $574.00 \dagger$ & 15.10 & -0.59 \\
\hline 21.51 & 585.00 & & -0.41 \\
\hline 21.71 & $596.00 \dagger$ & 15.30 & -1.45 \\
\hline 21.91 & 601.20 & & -0.61 \\
\hline 22.11 & 606.50 & & -0.37 \\
\hline 22.31 & 611.70 & & -0.42 \\
\hline 22.51 & $617.00 \dagger$ & 15.50 & -0.76 \\
\hline 22.71 & 622.50 & & -0.49 \\
\hline 22.91 & $628.00 \dagger$ & 16.22 & 0.48 \\
\hline 23.11 & 632.00 & & 0.32 \\
\hline 23.31 & 636.00 & & 0.30 \\
\hline 23.51 & 640.00 & & 0.25 \\
\hline 23.71 & 644.00 & & -0.02 \\
\hline 23.91 & 648.00 & & 0.03 \\
\hline 24.11 & 652.00 & & 0.06 \\
\hline 24.31 & $656.00 \dagger$ & 16.40 & 0.11 \\
\hline 24.51 & 662.60 & & -0.22 \\
\hline 24.71 & 669.20 & & -0.16 \\
\hline 24.91 & 675.80 & & -0.24 \\
\hline 25.11 & 682.40 & & -0.62 \\
\hline 25.31 & $689.00 \dagger$ & 17.30 & -0.87 \\
\hline 25.51 & 692.70 & & -0.38 \\
\hline 25.71 & 696.30 & & 0.16 \\
\hline 25.91 & $700.00^{+}$ & 18.23 & 0.05 \\
\hline 26.11 & 703.50 & & 0.18 \\
\hline 26.31 & 707.00 & & -0.21 \\
\hline 26.51 & 710.50 & & -0.03 \\
\hline 26.71 & 714.00 & & -0.43 \\
\hline 26.91 & 717.50 & & 0.10 \\
\hline 27.11 & $721.00 \dagger$ & 18.40 & -0.25 \\
\hline 27.31 & 723.90 & & -0.06 \\
\hline 27.51 & 726.70 & & -0.40 \\
\hline 27.71 & 729.60 & & -0.54 \\
\hline 27.81 & $731.00 \dagger$ & 19.10 & \\
\hline 27.91 & 733.80 & & -0.51 \\
\hline
\end{tabular}

Table 1 (continued).

\begin{tabular}{|c|c|c|c|}
\hline $\begin{array}{l}\text { Depth } \\
\text { in core } \\
(\mathrm{m})\end{array}$ & $\begin{array}{c}\text { Age } \\
\text { (k.y.B.P.) }\end{array}$ & $\begin{array}{c}\text { Stages } \\
\text { (Imbrie et al., } \\
\text { 1984) }\end{array}$ & $\begin{array}{c}\text { Oxygen } \\
\text { isotopes } \\
\text { (PDB) }\end{array}$ \\
\hline 28.11 & 739.30 & & -0.28 \\
\hline 28.31 & 744.90 & & -0.03 \\
\hline 28.51 & 750.40 & & 0.00 \\
\hline 28.71 & $756.00 \dagger$ & 20.24 & 0.11 \\
\hline 28.91 & 759.40 & & 0.01 \\
\hline 29.11 & 762.80 & & -0.54 \\
\hline 29.31 & 766.20 & & -0.52 \\
\hline 29.51 & 769.70 & & -0.61 \\
\hline 29.71 & 773.10 & & -0.88 \\
\hline 29.91 & 776.50 & & -0.47 \\
\hline 30.11 & 779.90 & & -0.97 \\
\hline 30.31 & 783.30 & & -0.94 \\
\hline 30.51 & 786.70 & & -0.87 \\
\hline 30.71 & 790.20 & & -0.30 \\
\hline 30.91 & 793.60 & & 0.13 \\
\hline 31.11 & $797.00 \dagger$ & & 0.19 \\
\hline 31.31 & 799.60 & & 0.18 \\
\hline 31.51 & 802.10 & & 0.04 \\
\hline 31.71 & 804.70 & & 0.13 \\
\hline 31.91 & 807.20 & & 0.01 \\
\hline 32.11 & 809.80 & & 0.03 \\
\hline 32.31 & 812.40 & & 0.12 \\
\hline 32.51 & 814.90 & & -0.02 \\
\hline 32.71 & $817.50 \dagger$ & & -0.45 \\
\hline 32.91 & 828.70 & & -0.03 \\
\hline 33.11 & $839.90 \dagger$ & & 0.21 \\
\hline 33.31 & 843.90 & & 0.00 \\
\hline 33.51 & 847.90 & & -0.05 \\
\hline 33.71 & 851.90 & & -0.18 \\
\hline 33.91 & 855.90 & & -0.75 \\
\hline 34.11 & 859.90 & & -0.57 \\
\hline 34.21 & $861.90 \dagger$ & & \\
\hline 34.31 & 864.70 & & -0.44 \\
\hline 34.51 & 870.30 & & -0.60 \\
\hline 34.71 & 875.80 & & -0.09 \\
\hline 34.91 & $881.40 \dagger$ & & -0.11 \\
\hline 35.11 & 884.40 & & -0.20 \\
\hline 35.31 & 887.40 & & -0.77 \\
\hline 35.51 & 890.40 & & -0.69 \\
\hline 35.71 & 893.50 & & -0.67 \\
\hline 35.91 & 896.50 & & -0.57 \\
\hline 36.11 & $899.50 \dagger$ & & -0.41 \\
\hline 36.51 & 909.30 & & -1.18 \\
\hline 36.71 & 914.20 & & -0.61 \\
\hline 36.91 & 919.10 & & -0.53 \\
\hline 37.01 & $921.50 \dagger$ & & \\
\hline 37.11 & 925.30 & & -0.45 \\
\hline 37.31 & 932.80 & & -0.69 \\
\hline 37.51 & 940.30 & & -1.22 \\
\hline 37.71 & $947.80 \dagger$ & & -0.82 \\
\hline 37.91 & 954.30 & & -1.11 \\
\hline 38.11 & 960.80 & & -0.64 \\
\hline 38.31 & 967.30 & & -0.69 \\
\hline 38.41 & $970.50 \dagger$ & & \\
\hline 38.51 & 973.10 & & -0.86 \\
\hline 38.71 & 978.20 & & -0.63 \\
\hline 39.11 & $988.40 \dagger$ & & -1.32 \\
\hline 39.31 & 990.60 & & -0.77 \\
\hline 39.51 & 992.90 & & -0.63 \\
\hline 39.71 & 995.10 & & -0.40 \\
\hline 39.91 & 997.30 & & -0.40 \\
\hline 40.11 & 999.50 & & -0.48 \\
\hline 40.31 & 1002.00 & & -0.28 \\
\hline 40.51 & $1004.00 \dagger$ & & -0.05 \\
\hline
\end{tabular}

\section{Discussion}

\section{Lithogenic MAR}

The lithogenic percent and MAR records show a strong negative correlation with the oxygen isotope record indicating increased dust accumulation during more arid, glacial periods. The glacial aridity of Somali (Street and Grove, 1979; Van Campo et al., 1982; Street-Perrott and Harrison, 1985), Arabia 
Table 2. Lithogenic data from Hole 722B.

\begin{tabular}{|c|c|c|c|c|c|c|c|c|c|c|c|}
\hline $\begin{array}{l}\text { Depth } \\
\text { in core } \\
(\mathrm{m})\end{array}$ & $\begin{array}{c}\text { Age } \\
\text { (k.y.B.P.) }\end{array}$ & $\begin{array}{l}\text { Dry bulk density } \\
\text { ( } \mathrm{g} \text { dry wt } / \mathrm{cm}^{3} \\
\text { wet vol.) }\end{array}$ & $\begin{array}{c}\text { Percent } \\
\text { lithogenic } \\
(\%)\end{array}$ & $\begin{array}{l}\text { Median } \\
\text { grain size } \\
\quad(\mu \mathrm{m})\end{array}$ & $\begin{array}{c}\text { Lithogenic } \\
\text { MAR } \\
\left.\text { (g/ } / \mathrm{cm}^{2} / \mathrm{k} . \mathrm{y}\right)\end{array}$ & $\begin{array}{l}\text { Depth } \\
\text { in core } \\
\text { (m) }\end{array}$ & $\begin{array}{c}\text { Age } \\
\text { (k.y.B.P.) }\end{array}$ & $\begin{array}{l}\text { Dry bulk density } \\
\text { (g dry wt } / \mathrm{cm}^{3} \\
\text { wet vol.) }\end{array}$ & $\begin{array}{l}\text { Percent } \\
\text { lithogenic } \\
(\%)\end{array}$ & $\begin{array}{l}\text { Median } \\
\text { grain size } \\
(\mu \mathrm{m})\end{array}$ & $\begin{array}{l}\text { Lithogenic } \\
\text { MAR } \\
\text { (g/cm } / \mathrm{cm}^{2} / \text { k.y.) }\end{array}$ \\
\hline 0.04 & 006.35 & 0.81 & 18.94 & 14.85 & 1.294 & 15.34 & 371.10 & 0.90 & 26.72 & 14.88 & 1.031 \\
\hline 0.24 & 008.71 & 0.81 & 17.96 & 12.92 & 1.233 & 15.54 & 375.90 & 0.92 & 24.57 & 13.56 & 0.839 \\
\hline 0.44 & 011.07 & 0.85 & 26.48 & 14.17 & 1.912 & 15.74 & 381.90 & 0.98 & 18.65 & 13.89 & 0.611 \\
\hline 0.64 & 013.43 & 0.91 & 44.77 & 13.98 & 3.439 & 15.94 & 387.90 & 1.02 & 20.61 & 13.36 & 0.697 \\
\hline 0.84 & 015.79 & 0.92 & 35.34 & 14.42 & 2.620 & 16.14 & 393.90 & 1.04 & 24.88 & 14.77 & 0.863 \\
\hline 1.04 & 018.42 & 0.87 & 33.99 & 14.36 & 1.760 & 16.34 & 399.90 & 0.91 & 13.99 & 12.92 & 0.368 \\
\hline 1.24 & 022.52 & 0.91 & 38.60 & 14.28 & 1.723 & 16.54 & 407.70 & 0.96 & 15.43 & 13.69 & 0.249 \\
\hline 1.44 & 026.62 & 0.91 & 32.85 & 14.71 & 1.450 & 16.74 & 423.50 & 0.97 & 15.76 & 13.67 & 0.314 \\
\hline 1.64 & 030.73 & 0.89 & 35.50 & 14.09 & 1.544 & 16.94 & 427.20 & 1.06 & 32.43 & 12.94 & 1.856 \\
\hline 1.84 & 034.83 & 0.88 & 32.34 & 14.64 & 1.390 & 17.14 & 430.90 & 1.08 & 38.15 & 14.62 & 2.186 \\
\hline 2.04 & 038.94 & 0.82 & 27.03 & 14.67 & 1.078 & 17.34 & 434.70 & 1.14 & 28.28 & 14.01 & 1.552 \\
\hline 2.24 & 043.04 & 0.88 & 30.65 & 14.88 & 1.309 & 17.54 & 439.20 & 1.05 & 31.02 & 15.53 & 1.442 \\
\hline 2.44 & 047.15 & 0.92 & 37.52 & 15.02 & 1.687 & 17.74 & 443.70 & 0.94 & 35.44 & 15.44 & 1.486 \\
\hline 2.64 & 051.25 & 0.88 & 23.08 & 15.99 & 0.988 & 17.94 & 448.20 & 1.03 & 33.05 & 14.99 & 1.509 \\
\hline 2.84 & 055.35 & 0.91 & 26.75 & 15.13 & 1.179 & 18.14 & 452.70 & 0.96 & 29.00 & 16.08 & 1.239 \\
\hline 3.04 & 059.46 & 0.90 & 27.89 & 14.35 & 1.221 & 18.34 & 457.20 & 0.98 & 27.80 & 15.40 & 1.216 \\
\hline 3.24 & 063.56 & 1.03 & 37.49 & 14.31 & 1.630 & 18.54 & 461.70 & 1.02 & 28.57 & 14.71 & 1.230 \\
\hline 3.44 & 068.90 & 1.04 & 37.67 & 15.57 & 1.380 & 18.74 & 466.70 & 0.92 & 29.21 & 16.19 & 1.038 \\
\hline 3.64 & 074.90 & 0.98 & 27.12 & 15.87 & 0.847 & 18.94 & 472.00 & 0.92 & 22.91 & 15.24 & 0.705 \\
\hline 3.84 & 081.42 & 0.94 & 28.61 & 14.02 & 0.673 & 19.14 & 478.70 & 0.98 & 27.80 & 14.05 & 0.822 \\
\hline 4.04 & 090.92 & 0.97 & 22.32 & 14.96 & 0.457 & 19.34 & 485.30 & 1.00 & 26.39 & 14.48 & 0.761 \\
\hline 4.24 & 100.40 & 0.87 & 19.90 & 14.73 & 0.370 & 19.54 & 492.60 & 0.94 & 25.80 & 15.26 & 0.529 \\
\hline 4.44 & 109.60 & 0.99 & 23.58 & 14.29 & 0.506 & 19.74 & 503.70 & 0.99 & 24.64 & 13.42 & 0.462 \\
\hline 4.64 & 118.80 & 0.92 & 28.85 & 13.82 & 0.735 & 19.94 & 513.70 & 1.05 & 34.52 & 14.50 & 1.006 \\
\hline 4.84 & 124.00 & 0.90 & 19.20 & 12.94 & 0.821 & 20.14 & 518.10 & 0.99 & 32.57 & 15.77 & 1.473 \\
\hline 5.04 & 127.20 & 0.88 & 35.89 & 13.86 & 2.005 & 20.34 & 522.50 & 1.01 & 26.23 & 18.29 & 0.879 \\
\hline 5.24 & 130.30 & 0.86 & 38.65 & 13.74 & 2.126 & 20.54 & 530.10 & 1.12 & 32.56 & 16.98 & 0.829 \\
\hline 5.43 & 133.30 & 0.84 & 37.15 & 14.52 & 1.977 & 20.74 & 540.10 & 1.03 & 27.40 & 15.33 & 0.478 \\
\hline 5.58 & 135.70 & 0.83 & 30.28 & 14.81 & 1.498 & 20.94 & 553.60 & 1.00 & 31.73 & 15.90 & 0.515 \\
\hline 5.74 & 138.50 & 0.98 & 32.06 & 14.91 & 1.791 & 21.14 & 564.60 & 1.00 & 26.99 & 17.52 & 0.490 \\
\hline 5.94 & 142.00 & 0.93 & 34.24 & 15.10 & 1.851 & 21.34 & 575.60 & 0.98 & 30.02 & 15.40 & 0.538 \\
\hline 6.14 & 145.40 & 1.00 & 38.86 & 14.57 & 2.250 & 21.54 & 586.60 & 1.00 & 28.67 & 16.76 & 0.542 \\
\hline 6.34 & 148.90 & 1.11 & 44.92 & 15.30 & 2.855 & 21.74 & 596.80 & 0.96 & 16.94 & 12.43 & 0.421 \\
\hline 6.54 & 152.40 & 1.05 & 39.31 & 15.26 & 2.365 & 21.94 & 602.00 & 1.04 & 28.94 & 14.32 & 1.143 \\
\hline 6.74 & 155.90 & 1.06 & 47.95 & 14.95 & 2.934 & 22.14 & 607.30 & 0.99 & 27.52 & 17.62 & 1.035 \\
\hline 6.94 & 159.30 & 1.08 & 50.96 & 14.98 & 3.178 & 22.34 & 612.50 & 1.00 & 29.46 & 14.99 & 1.118 \\
\hline 7.14 & 162.80 & 0.96 & 30.60 & 14.59 & 1.676 & 22.54 & 617.80 & 1.02 & 32.24 & 18.19 & 1.220 \\
\hline 7.34 & 166.30 & 0.97 & 33.53 & 15.29 & 1.849 & 22.74 & 623.30 & 1.10 & 40.94 & 14.45 & 1.661 \\
\hline 7.54 & 169.80 & 1.05 & 41.73 & 14.77 & 2.253 & 22.94 & 628.60 & 1.05 & 39.31 & 15.36 & 1.779 \\
\hline 7.74 & 174.10 & 1.03 & 34.09 & 15.13 & 1.546 & 23.14 & 632.60 & 1.04 & 36.77 & 16.09 & 1.910 \\
\hline 7.94 & 178.90 & 0.99 & 39.52 & 15.22 & 1.541 & 23.34 & 636.60 & 1.08 & 36.70 & 15.49 & 1.981 \\
\hline 8.14 & 184.30 & 1.03 & 35.07 & 16.16 & 1.007 & 23.54 & 640.60 & 1.06 & 31.48 & 15.43 & 1.673 \\
\hline 8.34 & 193.20 & 0.98 & 16.67 & 12.79 & 0.370 & 23.74 & 644.60 & 1.04 & 34.99 & 15.16 & 1.817 \\
\hline 8.54 & 202.00 & 0.91 & 20.46 & 14.58 & 0.422 & 23.94 & 648.60 & 1.06 & 32.87 & 15.86 & 1.745 \\
\hline 8.74 & 210.90 & 0.90 & 21.53 & 15.88 & 0.454 & 24.14 & 652.60 & 1.02 & 32.58 & 15.47 & 1.584 \\
\hline 8.94 & 219.00 & 0.86 & 15.48 & 12.91 & 0.443 & 24.34 & 657.00 & 0.99 & 38.59 & 14.57 & 1.385 \\
\hline 9.14 & 222.90 & 1.04 & 31.12 & 13.71 & 1.656 & 24.54 & 663.60 & 1.00 & 35.23 & 17.10 & 1.066 \\
\hline 9.34 & 226.80 & 1.05 & 37.17 & 13.91 & 1.994 & 24.74 & 670.20 & 0.98 & 34.48 & 14.79 & 1.021 \\
\hline 9.54 & 230.70 & 0.97 & 27.60 & 14.72 & 1.351 & 24.80 & 672.20 & 0.88 & 31.29 & 15.08 & 0.833 \\
\hline 9.74 & 234.70 & 1.02 & 27.77 & 15.32 & 1.459 & 24.94 & 676.80 & 0.88 & 21.99 & 17.05 & 0.586 \\
\hline 9.94 & 238.50 & 0.95 & 22.23 & 14.06 & 1.127 & 25.14 & 683.40 & 0.84 & 23.97 & 15.41 & 0.635 \\
\hline 10.14 & 242.20 & 0.96 & 31.94 & 13.81 & 1.658 & 25.34 & 689.50 & 0.91 & 23.34 & 16.40 & 0.866 \\
\hline 10.34 & 245.90 & 1.00 & 36.37 & 14.45 & 1.995 & 25.54 & 693.20 & 0.94 & 28.30 & 13.85 & 1.432 \\
\hline 1054 & 249.50 & 0.97 & 31.71 & 14.80 & 1.787 & 25.74 & 696.90 & 1.07 & 42.02 & 13.59 & 2.467 \\
\hline 10.74 & 252.80 & 0.93 & 27.04 & 15.34 & 1.507 & 25.94 & 700.50 & 1.21 & 45.58 & 13.62 & 3.101 \\
\hline 10.94 & 256.20 & 0.94 & 29.54 & 14.64 & 1.659 & 26.14 & 704.00 & 1.06 & 27.38 & 15.13 & 1.651 \\
\hline 11.14 & 259.50 & 0.94 & 28.92 & 14.85 & 1.655 & 26.34 & 707.50 & 0.96 & 30.50 & 15.05 & 1.678 \\
\hline 11.34 & 262.80 & 1.02 & 38.72 & 14.52 & 2.367 & 26.54 & 711.00 & 0.97 & 23.10 & 15.16 & 1.283 \\
\hline 11.54 & 266.20 & 1.02 & 40.92 & 14.37 & 2.216 & 26.74 & 714.50 & 0.85 & 22.24 & 14.39 & 1.080 \\
\hline 11.74 & 270.30 & 1.06 & 37.43 & 16.17 & 1.209 & 26.94 & 718.00 & 1.00 & 31.55 & 13.50 & 1.835 \\
\hline 11.94 & 279.30 & 1.06 & 27.78 & 15.25 & 0.670 & 27.14 & 721.40 & 0.96 & 23.63 & 14.04 & 1.435 \\
\hline 12.14 & 287.90 & 1.02 & 16.29 & 13.45 & 0.454 & 27.34 & 724.30 & 0.94 & 26.31 & 14.13 & 1.744 \\
\hline 12.34 & 293.90 & 1.05 & 19.24 & 14.29 & 0.656 & 27.54 & 727.10 & 0.94 & 26.78 & 14.23 & 1.768 \\
\hline 12.54 & 300.20 & 0.98 & 21.81 & 15.00 & 0.600 & 27.74 & 730.00 & 1.02 & 29.24 & 15.18 & 1.592 \\
\hline 12.74 & 308.20 & 0.97 & 19.59 & 13.60 & 0.474 & 27.94 & 734.60 & 1.00 & 26.27 & 14.98 & 1.028 \\
\hline 12.94 & 316.20 & 0.99 & 16.13 & 13.80 & 0.400 & 28.14 & 740.20 & 0.99 & 27.34 & 14.40 & 0.979 \\
\hline 13.14 & 324.20 & 0.87 & 16.75 & 13.87 & 0.385 & 28.34 & 745.70 & 0.98 & 36.52 & 13.96 & 1.288 \\
\hline 13.34 & 331.40 & 0.90 & 16.42 & 14.74 & 0.587 & 28.54 & 751.30 & 1.07 & 39.40 & 14.40 & 1.554 \\
\hline 13.54 & 334.30 & 0.91 & 18.48 & 12.70 & 1.185 & 28.74 & 756.50 & 1.04 & 36.13 & 14.52 & 1.752 \\
\hline 13.74 & 337.10 & 1.03 & 21.86 & 13.12 & 1.573 & 28.94 & 759.90 & 1.03 & 35.96 & 14.77 & 2.179 \\
\hline 13.94 & 340.00 & 1.02 & 28.26 & 13.70 & 1.702 & 29.14 & 763.30 & 0.98 & 27.76 & 16.73 & 1.579 \\
\hline 14.14 & 343.90 & 1.04 & 24.37 & 14.66 & 1.192 & 29.34 & 766.80 & 0.94 & 20.95 & 16.27 & 1.138 \\
\hline 14.34 & 348.50 & 1.05 & 27.91 & 14.91 & 1.292 & 29.54 & 770.20 & 0.85 & 18.43 & 14.66 & 0.917 \\
\hline 14.54 & 353.00 & 1.00 & 29.03 & 13.79 & 1.290 & 29.74 & 773.60 & 0.92 & 18.28 & 16.18 & 0.986 \\
\hline 14.74 & 357.50 & 0.96 & 31.18 & 13.54 & 1.329 & 29.94 & 777.00 & 0.95 & 22.08 & 16.25 & 1.231 \\
\hline 15.00 & 363.40 & 0.92 & 25.79 & 14.12 & 1.041 & 30.14 & 780.40 & 0.96 & 14.05 & 14.06 & 0.789 \\
\hline 15.14 & 366.60 & 0.89 & 23.89 & 13.01 & 0.942 & 30.34 & 783.80 & 0.98 & 22.92 & 15.41 & 1.309 \\
\hline
\end{tabular}

Table 2 (continued). 
Table 2 (continued).

\begin{tabular}{cccccc}
\hline $\begin{array}{c}\text { Depth } \\
\text { in core } \\
(\mathrm{m})\end{array}$ & $\begin{array}{c}\text { Age } \\
\text { (k.y.B.P.) }\end{array}$ & $\begin{array}{c}\text { Dry bulk density } \\
\text { (g dry wt/cm } \\
\text { wet vol.) }\end{array}$ & $\begin{array}{c}\text { Percent } \\
\text { lithogenic } \\
(\%)\end{array}$ & $\begin{array}{c}\text { Median } \\
\text { grain size } \\
(\mu \mathrm{m})\end{array}$ & $\begin{array}{c}\text { Lithogenic } \\
\text { MAR } \\
\left(\mathrm{g} / \mathrm{cm}^{2} / \mathrm{k} . \mathrm{y} \text { ) }\right.\end{array}$ \\
\hline 30.54 & 787.30 & 1.01 & 20.94 & 16.68 & 1.232 \\
30.74 & 790.70 & 0.93 & 27.86 & 13.94 & 1.530 \\
30.94 & 794.10 & 1.08 & 39.68 & 13.71 & 2.557 \\
31.14 & 797.40 & 1.04 & 39.38 & 15.65 & 2.827 \\
31.34 & 799.90 & 0.94 & 43.73 & 15.08 & 3.229 \\
31.54 & 802.50 & 1.09 & 37.79 & 15.02 & 3.168 \\
31.74 & 805.10 & 1.07 & 39.53 & 14.31 & 3.303 \\
31.94 & 807.60 & 1.15 & 46.20 & 14.19 & 4.183 \\
32.14 & 810.20 & 1.13 & 46.91 & 13.61 & 4.064 \\
32.34 & 812.80 & 1.02 & 31.55 & 15.79 & 2.517 \\
32.54 & 815.30 & 0.83 & 25.07 & 17.22 & 1.307 \\
32.74 & 819.20 & 0.93 & 25.81 & 16.48 & 0.634 \\
32.94 & 830.40 & 1.00 & 40.96 & 14.02 & 0.773 \\
33.14 & 840.50 & 1.19 & 46.47 & 16.00 & 1.574 \\
33.34 & 844.50 & 1.01 & 40.26 & 16.63 & 2.037 \\
33.54 & 848.50 & 1.15 & 41.26 & 15.77 & 2.374 \\
33.74 & 852.50 & 1.16 & 38.94 & 14.65 & 2.254 \\
33.94 & 856.50 & 1.10 & 36.00 & 17.04 & 1.984 \\
34.14 & 860.50 & 1.05 & 33.68 & 15.52 & 1.566 \\
34.34 & 865.50 & 0.99 & 34.52 & 14.92 & 1.369 \\
34.54 & 871.10 & 0.94 & 30.48 & 15.49 & 1.020 \\
34.74 & 876.70 & 1.11 & 37.02 & 13.47 & 1.523 \\
34.94 & 881.90 & 1.10 & 36.08 & 13.86 & 1.945 \\
35.14 & 884.90 & 1.15 & 29.50 & 15.69 & 2.264 \\
35.34 & 887.90 & 0.98 & 31.82 & 15.72 & 2.079 \\
35.54 & 890.90 & 0.98 & 28.29 & 13.76 & 1.848 \\
35.74 & 893.90 & 1.02 & 27.62 & 13.06 & 1.876 \\
35.94 & 896.90 & 0.95 & 22.08 & 14.84 & 1.326 \\
36.14 & 900.20 & 1.01 & 29.75 & 16.17 & 1.469 \\
36.34 & 905.10 & 0.94 & 26.65 & 16.07 & 1.017 \\
36.54 & 910.00 & 0.99 & 14.73 & 12.70 & 0.593 \\
36.74 & 914.90 & 1.10 & 32.51 & 14.17 & 1.455 \\
36.94 & 919.80 & 1.13 & 32.19 & 13.72 & 1.270 \\
37.14 & 926.40 & 1.00 & 25.48 & 15.33 & 0.725 \\
37.34 & 933.90 & 1.04 & 33.46 & 14.96 & 0.926 \\
37.54 & 941.40 & 1.04 & 32.60 & 14.57 & 0.908 \\
37.74 & 948.80 & 0.98 & 29.83 & 15.52 & 0.842 \\
37.94 & 955.30 & 0.96 & 30.04 & 17.57 & 0.830 \\
\hline & & & & & \\
\hline
\end{tabular}

(Van Campo et al., 1982), and Asia (Kukla, 1987; Kukla et al., 1988; Hovan et al., 1989) has been documented through the study of lake levels, pollen, and glacial loess sections. The relationship between increased glacial aridity and increased dust accumulation in Owen Ridge sediments has been investigated using sediments from piston core RC27-61 (Clemens and Prell, 1990). Clemens and Prell conclude that, over the primary Milankovitch periods $(100,41$, and $23 \mathrm{k} . \mathrm{y}$.), the lithogenic MAR is forced externally by orbital insolation and internally by global ice-volume through its influence on the hydrological cycle, resulting in increased aridity, decreased vegetation cover, and increased deflation during glacial intervals. Work on Hole 722B sediments indicates that these relationships can be confidently extended over the past million years.

Visual inspection of the Hole 722B lithogenic percent and MAR records indicates that a dominant, low frequency $(\sim 100$ k.y.) cyclicity is established between 600 and 700 k.y. (Fig. 3). A similar transition is seen in the Hole $722 \mathrm{~B} \delta^{18} \mathrm{O}$ record. The age of these transitions is consistent with that of the transition in the Site $607 \delta^{18} \mathrm{O}$ record from the North Atlantic (Ruddiman et al., 1989) supporting the hypothesis that lithogenic flux to the Arabian Sea is influenced by glacial-interglacial climate changes associated with global ice-volume. Even in the absence of the large-amplitude 100 k.y. cyclicity (700 to 1000 k.y.) the lithogenic MAR record is still highly correlated to the $\delta^{18} \mathrm{O}$ record. This suggests that aridity remains coupled to climatic changes associated with global ice-volume despite decreased ice-mass during this period.
In addition to these results, the Hole 722B MAR record allows us to address the Owen Ridge sediment budget on both geological and modern time-scales. Because Owen Ridge sediments (0-1 Ma) are composed largely of two components (lithogenic clastics and biogenic carbonate) and because the lithogenic flux and weight percent increase during glacial periods, we might attribute variation in the carbonate percent record to dilution by lithogenic material. We find that carbonate percent is negatively correlated with lithogenic percent but that the carbonate MAR is positively correlated with lithogenic MAR (see Murray and Prell, this volume) indicating that variation in the carbonate percent record is indeed a function of dilution by lithogenic material.

Considering the modern sediment budget, Nair et al., (1989) report a lithogenic flux of $2.64 \mathrm{~g}\left(\mathrm{~m}^{2} \cdot \mathrm{yr}\right)^{-1}$ based on a sediment trap deployed $\sim 70 \mathrm{~km}$ east-southeast of our study area ( $3000 \mathrm{~m}$ water depth). This is compared to a $10.4 \mathrm{~g}\left(\mathrm{~m}^{2} \cdot \mathrm{yr}\right)^{-1}$ estimate based on lithogenic MAR averaged over the Holocene for both RC27-61 and Hole 722B combined (2000 m water depth). Aerosol estimates indicate a flux of $8.0 \mathrm{~g}\left(\mathrm{~m}^{2} \cdot \mathrm{yr}\right)^{-1}$ to the seafloor (Savoie et al., 1987).

While the aerosol and sediment core estimates agree reasonably well, the trap estimate is low, accounting for only $25 \%$ of that estimated by the sediment cores; an unexpected result considering that the trap is located on the Indus Fan, $1000 \mathrm{~m}$ deeper than the ridge crest. Indus Fan core RC27-62 $\left(16^{\circ} 10^{\prime} \mathrm{N}, 60^{\circ} 41^{\prime} \mathrm{E}\right)$, located $\sim 25 \mathrm{~km}$ east-southeast of the trap, indicates an average lithogenic MAR of $18 \mathrm{~g}\left(\mathrm{~m}^{2} \cdot \mathrm{yr}\right)^{-1}$ at $4000 \mathrm{~m}$. These comparisons indicate an anomalous lithogenic flux during the deployment year or that the trap is an inefficient collector. Although the sediment trap data and the geological records are consistent in terms of the seasonality of lithogenic flux and the mechanism of lithogenic transport to the Arabian Sea (see "Background and Previous Work" section), they are not consistent in their estimates of absolute fluxes.

\section{Lithogenic Grain Size}

The grain-size record is not well correlated to either the lithogenic percent or MAR records. Unlike the lithogenic percent and MAR, the grain size is a relatively high-frequency record and does not exhibit a clear visual correlation with the $\delta^{18} \mathrm{O}$ record. These observations indicate that (1) monsoon wind-strength has a somewhat more complex response to climatic forcing mechanisms than does aridity and (2) source-area aridity is not necessarily dependent on monsoon strength.

Analysis of core RC27-61 indicates that the grain-size record has significant coherency with the Earth's orbital precession band, with global ice volume $\left(\delta^{18} \mathrm{O}\right)$, and with latent-heat availability as monitored by Southern Hemisphere Indian Ocean sea surface temperature (SST). The phase relationships between these records (Fig. 2) indicate that the grain-size record is externally forced by precessional insolation, and internally forced by interactions between global ice volume and the availability of latent heat, both of which act in similar directions to determine the strength of the summer monsoon winds (Clemens and Prell, 1990). Analysis of the grain-size record from Hole 722B indicates that these relationships do not change appreciably over the past million years. We do, however, find a consistent phase discrepancy between records from RC27-61 and Hole 722B whereby RC27-61 leads Hole 722B (1-3 k.y.) over all Milankovitch bands for both the lithogenic and carbonate components. This is also true, though to a much lesser extent ( $<1$ k.y.), for the oxygen isotope records. We find that these discrepancies occur over the section of the record ( $0-600$ k.y.; Fig. 4) where the low sedimentation rate intervals average $\sim 2 \mathrm{~cm} / \mathrm{k} . \mathrm{y}$. and are of long duration. Over the section of the record in which the low sedimenta- 

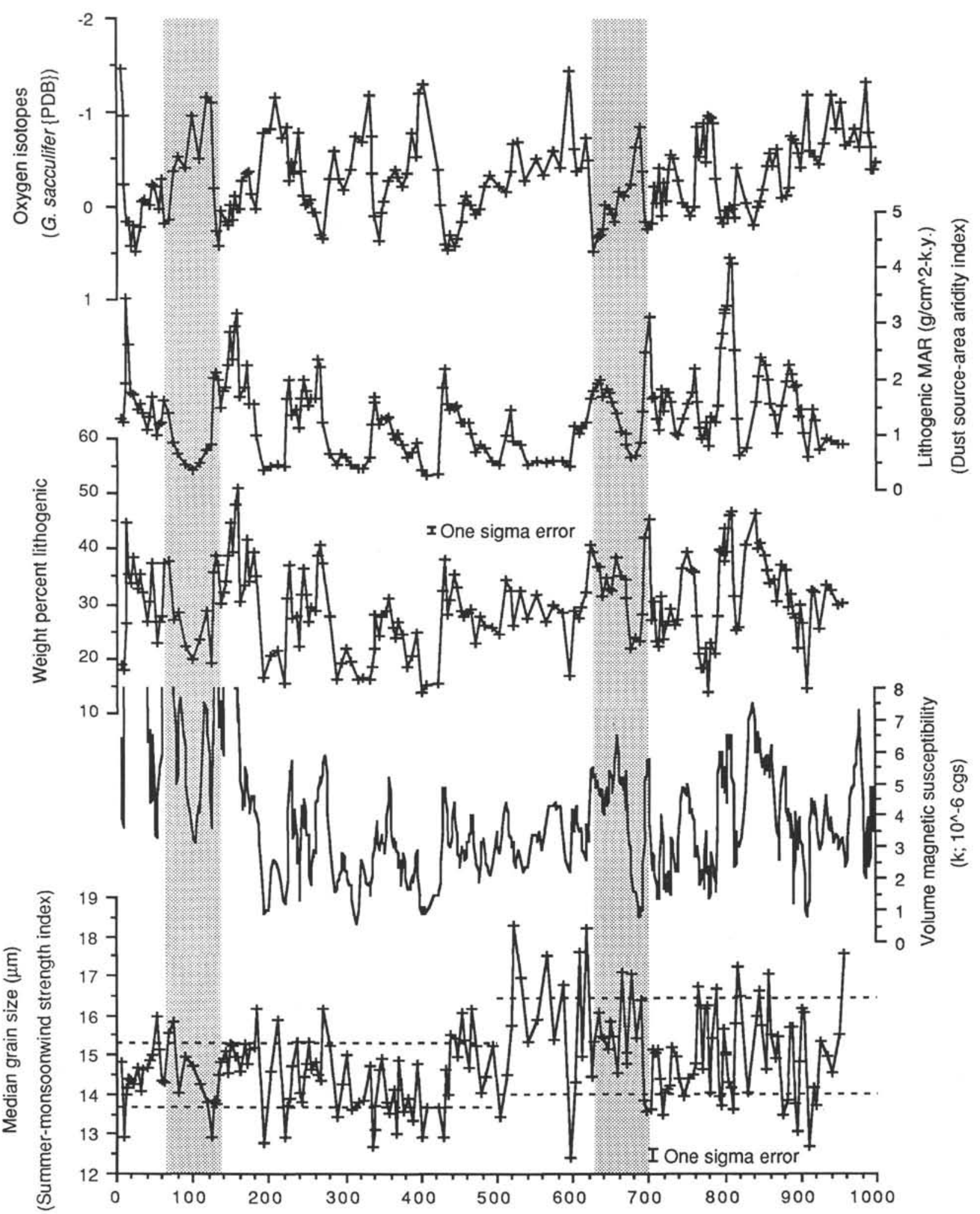

K.Y.B.P.

Figure 3. Time series plots of climatic indices from Site 722. From top to bottom; $\delta^{18} \mathrm{O}$, lithogenic MAR (dust source-area aridity), lithogenic percent, volume magnetic susceptibility, and median grain-size diameter (summer monsoon wind-strength). Both the lithogenic percent and MAR records show a strong negative correlation with the isotope record. Unlike the lithogenic percent and MAR, the grain size (summer monsoon wind-strength) exhibits higher frequency variability and shows no clear visual correlation with the isotope record. The magnetic susceptibility record is well correlated with the lithogenic percent record. The dashed lines on the grain-size record represent one standard deviation about the mean for the intervals 0 500 k.y. and 500-954 k.y. 
tion rate intervals are short in duration and average $\sim 3 \mathrm{~cm} / \mathrm{k} . \mathrm{y}$, the phases compare well (600-954 k.y.; Fig. 4). We thus conclude that the phase differences can be attributed to the lower resolution sampling interval used in Hole 722B compared to that used for RC27-61 $(20 \mathrm{~cm}$ compared to $10 \mathrm{~cm})$.

A first-order interpretation of the upcore grain-size decrease is that it indicates a decrease in summer monsoon wind-strength. The dashed lines (Fig. 3) represent one standard deviation about the mean for the intervals 0-500 k.y. and 500-954 k.y. The lower standard deviation lines over both intervals vary little compared to the upper lines indicating that the weaker monsoons remained unchanged but that the stronger monsoons became weaker over the interval $500 \mathrm{k}$.y. to present. The grain-size change, however, is not paralleled in the Globigerina bulloides upwelling record, an independent record of wind-strength (Prell, this volume). We take this to indicate (1) a decoupling of the two records over the interval from 500 to 954 k.y., or (2) that the change in the grain-size record is not the result of a change in monsoon strength but possibly a change in the lithogenic source. For example, the loss of a nearby source-area could account for a grain-size decrease without a change in windstrength nor a measurable change in the total flux. Such change could be accomplished via physical mechanisms related to lofting potential of lithogenic material or by a shift in wind patterns or direction. The Pliocene-Pleistocene orogeny of the Zagros mountains and the associated development of the modern Persian Gulf (Kassler, 1973) are local tectonic events that could certainly influence source-area lithology, distribution, and local wind patterns especially in terms of the northwesterly Shamal winds over Arabia (Pye, 1987).

Finally, we point out that the abrupt decrease in grain size occurs about 100 k.y. after the transition to dominant 100 k.y. cyclicity in the $\delta^{18} \mathrm{O}$, lithogenic percent, and lithogenic MAR records but simultaneously(?) with the disappearance of spectral power near the 41 k.y. obliquity periodicity (discussed below). This indicates that the change is not related to large-scale vegetation changes (due to aridity) or to source-area differences related to sea-level changes but that it may be causally related to a change in the sensitivity of monsoon strength to insolation forcing over the obliquity band.

We are thus left with competing hypotheses to be addressed in future work. The decoupling of the grain size and $G$. bulloi- des records can be tested by spectral comparisons over the interval from 500 to $954 \mathrm{k} . \mathrm{y}$. The hypothesis postulating changing source-areas can be tested by investigating changes in the mineralogical composition of the sediments across the transition; sediments from different source-areas may have different compositions. The synchronous(?) relationship between the decrease in grain size and the loss of spectral power near the 41 k.y. periodicity can be evaluated using evolutive spectral analysis, a technique applied in order to look at the evolution of spectral power in a time-series record (Pestiaux and Berger, 1984; Berger and Tricot, 1986).

\section{Intercore Reproducibility of the Lithogenic Record}

A primary concern in the generation and interpretation of paleoceanographic data is its reproducibility both in terms of laboratory technique (see "Methods" section) and core-to-core reproducibility. Reproducibility between cores is one measure of the regional/local homogeneity or stability of depositional processes. Documenting reproducibility is an important step in establishing the credibility of paleoceanographic data. However, the replication of records is both expensive and time-intensive and is often not accomplished.

Here we compare lithogenic measurements from Hole 722B with those from piston core RC27-61 (Clemens and Prell, 1990). Both cores are located atop the Owen Ridge, separated by only $6 \mathrm{~km}$ and $140 \mathrm{~m}$ water depth. The comparisons indicate that the major and most minor features of both records are reproducible on a core-to-core basis (Fig. 5).

\section{Discussion}

The weight percent and grain-size variations are similarly preserved core-to-core despite $25 \%$ greater sedimentation rate in Hole 722B compared to RC27-61. We interpret the reproducibility of the lithogenic records as indicating that the eolian depositional signal is regionally strong, coherent, and well preserved.

The lower sedimentation rate in RC27-61 indicates possible winnowing of the fine fraction (lithogenic and/or carbonate) and/or a difference in trapping efficiency (pre-depositional winnowing). If these mechanisms involve the lithogenic component, we might expect RC27-61 to exhibit lower lithogenic percent and larger grain size compared to Hole 722B. This is not the case (Fig. 5), indicating that either the decrease in sedimentation

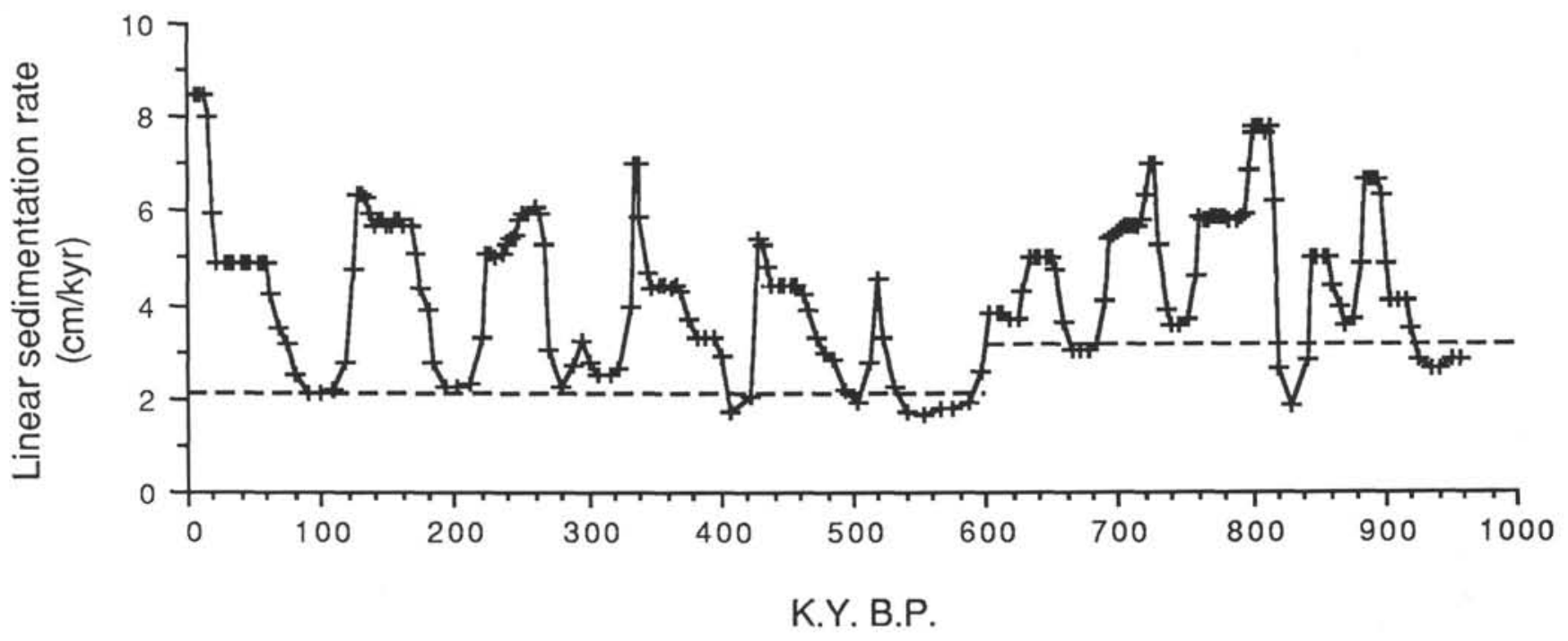

Figure 4. Linear sedimentation rate model for Hole 722B. Horizontal dashed lines indicate the average of the low sedimentation rate intervals for the periods $0-600 \mathrm{k} . \mathrm{y}$. and $600-955 \mathrm{k} . \mathrm{y}$. 

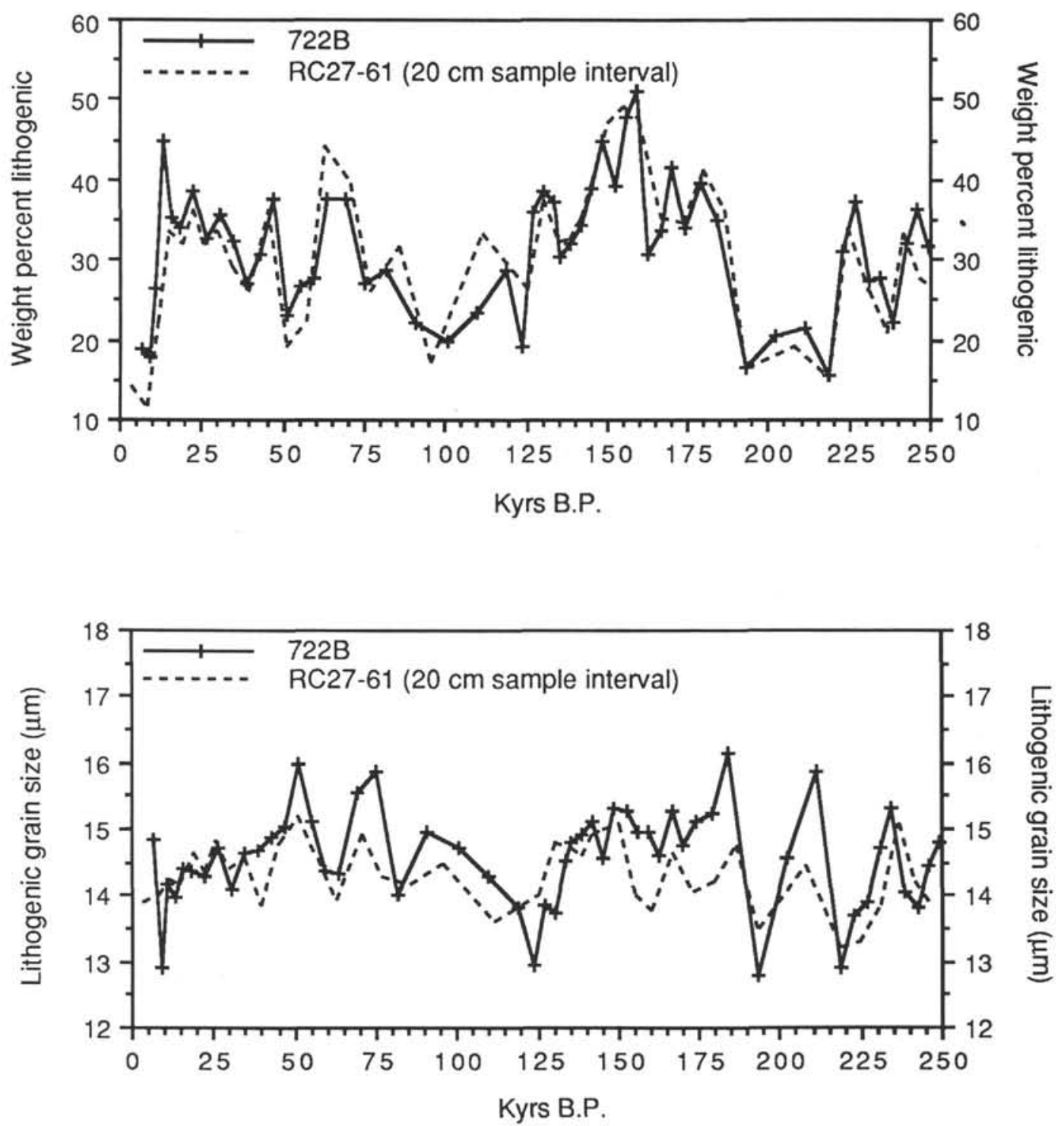

Figure 5. Comparison between Hole 722B and RC27-61 lithogenic percent and grain-size records from the Owen Ridge. Good reproducibility core-to-core indicates that the lithogenic measurements are robust and not degraded by minor differences in local depositional dynamics.

rate is not due to changes in the lithogenic component or that the percent and median grain-size measurements are not sensitive to such differences.

\section{Paleoclimatic Implications of Magnetic Susceptibility}

The magnetic susceptibility of deep-sea sediments, a measure of the ease with which the sediment can be magnetized, depends upon the concentration of ferrimagnetic minerals (primarily magnetite), usually occurring in trace amounts (Thompson and Oldfield, 1986; p. 21-38, 141-152). The origin of ferrimagnetic minerals in deep-sea sediments is primarily lithogenic but can also be biogenic, diagenetic, cosmic, and hydrogenous (Thompson and Oldfield, 1986; p. 141-152). The lithogenic record from Hole $722 \mathrm{~B}$ provides an ideal data set with which to constrain the origin of magnetically susceptible material found in Owen Ridge sediments (Table 3; Shipboard Scientific Party, Site 722) and the utility of the susceptibility signal as a paleoclimatic indicator.
Visual comparison between the susceptibility and lithogenic data (Fig. 3) shows that, except for the upper 190 k.y., the lithogenic percent and the volume magnetic susceptibility records are nearly identical in both the timing and relative amplitude of major and minor events. The high-amplitude magnetic susceptibility signal in the upper 190 k.y. (possibly diagenetic in nature) has been truncated in order to make a detailed comparison over the larger interval from 190 to 954 k.y. More rigorous comparisons between the magnetic susceptibility and the lithogenic percent can be accomplished through the use of simple regression and cross spectral analysis.

A simple linear regression between the lithogenic percent and magnetic susceptibility, over the interval from 190 to 954 k.y., indicates a strong positive relationship $(\mathrm{R}=0.91, \mathrm{n}=150$; Fig. 6A). This strong correlation is also found in the frequency domain (Fig. 6B). Cross-spectral comparison shows very strong coherency and zero phase relationships over the entire spectrum indicating a positive linear relationship between increased con- 
Table 3. Volume magnetic susceptibility data from Hole 722B (Shipboard Scientific Party, 1989).

\begin{tabular}{|c|c|c|}
\hline $\begin{array}{l}\text { Depth } \\
\text { in core } \\
(\mathrm{m})\end{array}$ & $\begin{array}{c}\text { Age } \\
\text { (k.y.B.P.) }\end{array}$ & $\begin{array}{l}\text { Volume magnetic } \\
\text { susceptibility } \\
\left(\mathrm{k}=10^{-6} \mathrm{cgs}\right)\end{array}$ \\
\hline 0.05 & 6.00 & 6.4 \\
\hline 0.10 & 7.06 & 5.4 \\
\hline 0.15 & 7.65 & 3.9 \\
\hline 0.20 & 8.24 & 3.6 \\
\hline 0.25 & 8.83 & 3.8 \\
\hline 0.30 & 9.42 & 6.5 \\
\hline 0.35 & 10.01 & 14.4 \\
\hline 0.40 & 10.60 & 11.2 \\
\hline 0.45 & 11.19 & 10.0 \\
\hline 0.50 & 11.78 & 12.7 \\
\hline 0.55 & 12.37 & 18.0 \\
\hline 0.60 & 12.96 & 21.6 \\
\hline 0.65 & 13.55 & 21.2 \\
\hline 0.70 & 14.14 & 17.0 \\
\hline 0.75 & 14.73 & 14.3 \\
\hline 0.80 & 15.32 & 14.0 \\
\hline 0.85 & 15.91 & 13.9 \\
\hline 0.90 & 16.50 & 14.8 \\
\hline 0.95 & 17.09 & 14.6 \\
\hline 1.00 & 17.68 & 14.2 \\
\hline 1.05 & 18.62 & 13.1 \\
\hline 1.10 & 19.65 & 13.4 \\
\hline 1.15 & 20.67 & 15.3 \\
\hline 1.20 & 21.70 & 16.1 \\
\hline 1.25 & 22.73 & 14.8 \\
\hline 1.30 & 23.75 & 13.1 \\
\hline 1.35 & 24.78 & 12.0 \\
\hline 1.40 & 25.80 & 11.0 \\
\hline 1.45 & 26.83 & 9.0 \\
\hline 1.55 & 28.88 & 16.2 \\
\hline 1.60 & 29.91 & 15.4 \\
\hline 1.65 & 30.93 & 13.8 \\
\hline 1.70 & 31.96 & 14.1 \\
\hline 1.75 & 32.99 & 13.8 \\
\hline 1.80 & 34.01 & 12.6 \\
\hline 1.85 & 35.04 & 12.5 \\
\hline 1.90 & 36.06 & 15.8 \\
\hline 1.95 & 37.09 & 13.9 \\
\hline 2.00 & 38.12 & 9.8 \\
\hline 2.05 & 39.14 & 7.9 \\
\hline 2.10 & 40.17 & 7.8 \\
\hline 2.15 & 41.19 & 6.3 \\
\hline 2.20 & 42.22 & 6.7 \\
\hline 2.25 & 43.25 & 5.8 \\
\hline 2.30 & 44.27 & 4.4 \\
\hline 2.35 & 45.30 & 4.5 \\
\hline 2.40 & 46.33 & 5.9 \\
\hline 2.45 & 47.35 & 6.5 \\
\hline 2.50 & 48.38 & 4.7 \\
\hline 2.55 & 49.40 & 4.0 \\
\hline 2.60 & 50.43 & 3.4 \\
\hline 2.65 & 51.46 & 3.3 \\
\hline 2.70 & 52.48 & 3.7 \\
\hline 2.75 & 53.51 & 4.6 \\
\hline 2.80 & 54.53 & 5.4 \\
\hline 2.85 & 55.56 & 5.4 \\
\hline 2.90 & 56.59 & 5.5 \\
\hline 2.95 & 57.61 & 5.9 \\
\hline 3.05 & 59.66 & 11.8 \\
\hline 3.10 & 60.69 & 17.4 \\
\hline 3.15 & 61.72 & 19.9 \\
\hline 3.20 & 62.74 & 20.1 \\
\hline 3.25 & 63.77 & 18.4 \\
\hline 3.30 & 64.79 & 16.3 \\
\hline 3.35 & 66.20 & 15.9 \\
\hline 3.40 & 67.70 & 15.2 \\
\hline 3.45 & 69.20 & 14.8 \\
\hline 3.50 & 70.70 & 13.4 \\
\hline 3.55 & 72.20 & 12.3 \\
\hline 3.60 & 73.70 & 10.3 \\
\hline 3.65 & 75.20 & 7.8 \\
\hline 3.70 & 76.70 & 6.6 \\
\hline 3.75 & 78.20 & 5.0 \\
\hline 3.80 & 79.70 & 5.3 \\
\hline 3.85 & 81.90 & 7.2 \\
\hline
\end{tabular}

Table 3 (continued).

\begin{tabular}{|c|c|c|}
\hline $\begin{array}{l}\text { Depth } \\
\text { in core } \\
(\mathrm{m})\end{array}$ & $\begin{array}{c}\text { Age } \\
\text { (k.y.B.P.) }\end{array}$ & $\begin{array}{l}\text { Volume magnetic } \\
\text { susceptibility } \\
\left(\mathrm{k}=10^{-6} \mathrm{cgs}\right)\end{array}$ \\
\hline 3.90 & 84.27 & 7.7 \\
\hline 3.95 & 86.65 & 6.6 \\
\hline 4.00 & 89.02 & 6.2 \\
\hline 4.05 & 91.40 & 5.0 \\
\hline 4.10 & 93.78 & 4.4 \\
\hline 4.15 & 96.15 & 4.0 \\
\hline 4.20 & 98.52 & 3.4 \\
\hline 4.25 & 100.80 & 3.3 \\
\hline 4.30 & 103.10 & 3.1 \\
\hline 4.35 & 105.40 & 4.0 \\
\hline 4.40 & 107.70 & 4.4 \\
\hline 4.45 & 110.00 & 4.1 \\
\hline 4.55 & 114.60 & 7.5 \\
\hline 4.60 & 116.90 & 7.3 \\
\hline 4.65 & 119.20 & 6.6 \\
\hline 4.70 & 121.50 & 6.0 \\
\hline 4.75 & 122.60 & 4.9 \\
\hline 4.80 & 123.40 & 3.6 \\
\hline 4.85 & 124.20 & 3.8 \\
\hline 4.90 & 125.00 & 4.6 \\
\hline 4.95 & 125.80 & 10.8 \\
\hline 5.00 & 126.50 & 13.3 \\
\hline 5.05 & 127.30 & 11.8 \\
\hline 5.10 & 128.10 & 11.8 \\
\hline 5.15 & 128.90 & 10.1 \\
\hline 5.20 & 129.70 & 10.3 \\
\hline 5.25 & 130.50 & 9.9 \\
\hline 5.30 & 131.20 & 8.9 \\
\hline 5.35 & 132.00 & 7.8 \\
\hline 5.40 & 132.80 & 7.3 \\
\hline 5.45 & 133.60 & 6.8 \\
\hline 5.50 & 134.40 & 7.2 \\
\hline 5.55 & 135.20 & 7.6 \\
\hline 5.60 & 136.00 & 6.7 \\
\hline 5.65 & 136.90 & 6.1 \\
\hline 5.70 & 137.80 & 6.8 \\
\hline 5.75 & 138.70 & 5.9 \\
\hline 5.80 & 139.50 & 6.6 \\
\hline 5.85 & 140.40 & 7.7 \\
\hline 5.90 & 141.30 & 8.8 \\
\hline 5.95 & 142.10 & 9.1 \\
\hline 6.00 & 143.00 & 9.7 \\
\hline 6.05 & 143.90 & 11.2 \\
\hline 6.10 & 144.70 & 12.8 \\
\hline 6.15 & 145.60 & 14.5 \\
\hline 6.20 & 146.50 & 16.7 \\
\hline 6.25 & 147.30 & 20.2 \\
\hline 6.30 & 148.20 & 21.8 \\
\hline 6.35 & 149.10 & 21.3 \\
\hline 6.40 & 150.00 & 20.5 \\
\hline 6.45 & 150.80 & 16.5 \\
\hline 6.50 & 151.70 & 12.9 \\
\hline 6.55 & 152.60 & 10.1 \\
\hline 6.60 & 153.40 & 8.8 \\
\hline 6.65 & 154.30 & 8.0 \\
\hline 6.70 & 155.20 & 8.4 \\
\hline 6.75 & 156.00 & 8.5 \\
\hline 6.80 & 156.90 & 8.1 \\
\hline 6.85 & 157.80 & 7.2 \\
\hline 6.90 & 158.70 & 7.0 \\
\hline 6.95 & 159.50 & 8.1 \\
\hline 7.05 & 161.30 & 5.6 \\
\hline 7.10 & 162.10 & 5.3 \\
\hline 7.15 & 163.00 & 5.1 \\
\hline 7.20 & 163.90 & 4.7 \\
\hline 7.25 & 164.70 & 4.2 \\
\hline 7.30 & 165.60 & 4.3 \\
\hline 7.35 & 166.50 & 4.3 \\
\hline 7.40 & 167.30 & 4.3 \\
\hline 7.45 & 168.20 & 4.7 \\
\hline 7.50 & 169.10 & 5.5 \\
\hline 7.55 & 170.00 & 5.2 \\
\hline 7.60 & 170.80 & 5.0 \\
\hline 7.65 & 172.00 & 4.9 \\
\hline 7.70 & 173.20 & 4.4 \\
\hline 7.75 & 174.40 & 4.1 \\
\hline 7.80 & 175.60 & 4.6 \\
\hline
\end{tabular}


S. C. CLEMENS, W. L. PRELL

Table 3 (continued).

\begin{tabular}{|c|c|c|}
\hline $\begin{array}{l}\text { Depth } \\
\text { in core } \\
(\mathrm{m})\end{array}$ & $\begin{array}{c}\text { Age } \\
\text { (k.y.B.P.) }\end{array}$ & $\begin{array}{l}\text { Volume magnetic } \\
\text { susceptibility } \\
\left(\mathrm{k}=10^{-6} \mathrm{cgs}\right)\end{array}$ \\
\hline 7.85 & 176.80 & 4.6 \\
\hline 7.90 & 178.00 & 4.5 \\
\hline 7.95 & 179.20 & 4.6 \\
\hline 8.00 & 180.40 & 4.5 \\
\hline 8.05 & 181.60 & 4.2 \\
\hline 8.10 & 182.80 & 4.0 \\
\hline 8.15 & 184.80 & 3.7 \\
\hline 8.20 & 187.00 & 3.1 \\
\hline 8.25 & 189.20 & 2.2 \\
\hline 8.30 & 191.40 & 1.1 \\
\hline 8.35 & 193.60 & 0.9 \\
\hline 8.40 & 195.80 & 1.0 \\
\hline 8.45 & 198.00 & 1.0 \\
\hline 8.55 & 202.50 & 2.3 \\
\hline 8.60 & 204.70 & 2.6 \\
\hline 8.65 & 206.90 & 2.5 \\
\hline 8.70 & 209.10 & 2.5 \\
\hline 8.75 & 211.30 & 2.3 \\
\hline 8.80 & 213.50 & 1.9 \\
\hline 8.85 & 215.70 & 1.9 \\
\hline 8.90 & 218.00 & 1.3 \\
\hline 8.95 & 219.20 & 1.2 \\
\hline 9.00 & 220.20 & 1.4 \\
\hline 9.05 & 221.10 & 1.4 \\
\hline 9.10 & 222.10 & 1.9 \\
\hline 9.15 & 223.10 & 3.3 \\
\hline 9.20 & 224.10 & 4.1 \\
\hline 9.25 & 225.10 & 4.1 \\
\hline 9.30 & 226.00 & 5.1 \\
\hline 9.35 & 227.00 & 5.4 \\
\hline 9.40 & 228.00 & 5.1 \\
\hline 9.45 & 229.00 & 5.7 \\
\hline 9.50 & 230.00 & 3.4 \\
\hline 9.55 & 230.90 & 3.3 \\
\hline 9.60 & 231.90 & 3.5 \\
\hline 9.65 & 232.90 & 4.1 \\
\hline 9.70 & 233.90 & 4.2 \\
\hline 9.75 & 234.90 & 3.4 \\
\hline 9.80 & 235.80 & 3.0 \\
\hline 9.85 & 236.80 & 2.5 \\
\hline 9.90 & 237.80 & 2.5 \\
\hline 9.95 & 238.70 & 1.6 \\
\hline 10.00 & 239.60 & 1.3 \\
\hline 10.05 & 240.60 & 2.4 \\
\hline 10.10 & 241.50 & 4.0 \\
\hline 10.15 & 242.40 & 4.1 \\
\hline 10.20 & 243.30 & 4.3 \\
\hline 10.25 & 244.20 & 3.6 \\
\hline 10.30 & 245.10 & 3.7 \\
\hline 10.35 & 246.10 & 4.5 \\
\hline 10.40 & 247.00 & 4.1 \\
\hline 10.45 & 247.90 & 3.6 \\
\hline 10.50 & 248.80 & 3.6 \\
\hline 10.55 & 249.70 & 3.4 \\
\hline 10.60 & 250.50 & 3.4 \\
\hline 10.65 & 251.30 & 3.2 \\
\hline 10.70 & 252.20 & 2.9 \\
\hline 10.75 & 253.00 & 2.1 \\
\hline 10.80 & 253.80 & 1.8 \\
\hline 10.85 & 254.70 & 1.8 \\
\hline 10.90 & 255.50 & 2.4 \\
\hline 10.95 & 256.30 & 2.9 \\
\hline 11.00 & 257.20 & 2.7 \\
\hline 11.05 & 258.00 & 2.7 \\
\hline 11.10 & 258.80 & 2.9 \\
\hline 11.15 & 259.70 & 2.8 \\
\hline 11.20 & 260.50 & 3.5 \\
\hline 11.25 & 261.30 & 3.6 \\
\hline 11.30 & 262.20 & 4.4 \\
\hline 11.35 & 263.00 & 4.5 \\
\hline 11.40 & 263.80 & 4.7 \\
\hline 11.45 & 264.70 & 4.8 \\
\hline 11.55 & 266.30 & 5.1 \\
\hline 11.60 & 267.20 & 5.2 \\
\hline 11.65 & 268.00 & 5.0 \\
\hline 11.70 & 268.80 & 5.3 \\
\hline 11.75 & 270.80 & 5.6 \\
\hline
\end{tabular}

Table 3 (continued).

\begin{tabular}{|c|c|c|}
\hline $\begin{array}{l}\text { Depth } \\
\text { in core } \\
(\mathrm{m})\end{array}$ & $\begin{array}{c}\text { Age } \\
\text { (k.y.B.P.) }\end{array}$ & $\begin{array}{l}\text { Volume magnetic } \\
\text { susceptibility } \\
\left(\mathrm{k}=10^{-6} \mathrm{cgs}\right)\end{array}$ \\
\hline 11.80 & 273.00 & 5.9 \\
\hline 11.85 & 275.30 & 5.3 \\
\hline 11.90 & 277.50 & 4.1 \\
\hline 11.95 & 279.80 & 3.0 \\
\hline 12.00 & 282.00 & 2.2 \\
\hline 12.05 & 284.30 & 1.6 \\
\hline 12.10 & 286.50 & 1.6 \\
\hline 12.15 & 288.20 & 1.7 \\
\hline 12.20 & 289.70 & 1.9 \\
\hline 12.25 & 291.20 & 2.0 \\
\hline 12.30 & 292.70 & 2.1 \\
\hline 12.35 & 294.20 & 2.3 \\
\hline 12.40 & 295.70 & 2.8 \\
\hline 12.45 & 297.20 & 2.7 \\
\hline 12.50 & 298.70 & 2.3 \\
\hline 12.55 & 300.60 & 2.2 \\
\hline 12.60 & 302.60 & 2.0 \\
\hline 12.65 & 304.60 & 1.8 \\
\hline 12.70 & 306.60 & 1.8 \\
\hline 12.75 & 308.60 & 1.3 \\
\hline 12.80 & 310.60 & 0.9 \\
\hline 12.85 & 312.60 & 0.6 \\
\hline 12.90 & 314.60 & 0.6 \\
\hline 12.95 & 316.60 & 1.0 \\
\hline 13.05 & 320.60 & 2.6 \\
\hline 13.10 & 322.60 & 2.4 \\
\hline 13.15 & 324.60 & 2.0 \\
\hline 13.20 & 326.60 & 1.9 \\
\hline 13.25 & 328.60 & 1.8 \\
\hline 13.30 & 330.60 & 1.8 \\
\hline 13.35 & 331.60 & 1.9 \\
\hline 13.40 & 332.30 & 1.7 \\
\hline 13.45 & 333.00 & 1.5 \\
\hline 13.50 & 333.70 & 1.8 \\
\hline 13.55 & 334.40 & 2.1 \\
\hline 13.60 & 335.10 & 2.6 \\
\hline 13.65 & 335.90 & 2.6 \\
\hline 13.70 & 336.60 & 2.7 \\
\hline 13.75 & 337.30 & 3.0 \\
\hline 13.80 & 338.00 & 3.3 \\
\hline 13.85 & 338.70 & 3.2 \\
\hline 13.90 & 339.40 & 3.1 \\
\hline 13.95 & 340.10 & 3.7 \\
\hline 14.00 & 340.90 & 3.8 \\
\hline 14.05 & 341.90 & 3.8 \\
\hline 14.10 & 343.00 & 3.2 \\
\hline 14.15 & 344.20 & 2.9 \\
\hline 14.20 & 345.30 & 3.0 \\
\hline 14.25 & 346.40 & 3.4 \\
\hline 14.30 & 347.60 & 3.2 \\
\hline 14.35 & 348.70 & 3.1 \\
\hline 14.40 & 349.80 & 3.1 \\
\hline 14.45 & 351.00 & 2.8 \\
\hline 14.55 & 353.20 & 3.5 \\
\hline 14.60 & 354.40 & 3.6 \\
\hline 14.65 & 355.50 & 3.9 \\
\hline 14.70 & 356.60 & 4.4 \\
\hline 14.75 & 357.80 & 5.2 \\
\hline 14.80 & 358.90 & 4.7 \\
\hline 14.85 & 360.00 & 3.7 \\
\hline 14.90 & 361.20 & 3.4 \\
\hline 14.95 & 362.30 & 3.0 \\
\hline 15.00 & 363.40 & 3.3 \\
\hline 15.05 & 364.60 & 3.3 \\
\hline 15.10 & 365.70 & 2.9 \\
\hline 15.15 & 366.80 & 3.2 \\
\hline 15.20 & 368.00 & 2.9 \\
\hline 15.25 & 369.10 & 2.8 \\
\hline 15.30 & 370.20 & 2.4 \\
\hline 15.35 & 371.40 & 2.6 \\
\hline 15.40 & 372.50 & 2.2 \\
\hline 15.45 & 373.60 & 1.8 \\
\hline 15.50 & 374.80 & 2.6 \\
\hline 15.55 & 376.20 & 2.8 \\
\hline 15.60 & 377.70 & 2.5 \\
\hline 15.65 & 379.20 & 2.0 \\
\hline 15.70 & 380.70 & 1.7 \\
\hline
\end{tabular}


Table 3 (continued).

\begin{tabular}{|c|c|c|}
\hline $\begin{array}{l}\text { Depth } \\
\text { in core } \\
(\mathrm{m})\end{array}$ & $\begin{array}{c}\text { Age } \\
\text { (k.y.B.P.) }\end{array}$ & $\begin{array}{l}\text { Volume magnetic } \\
\text { susceptibility } \\
\left(\mathrm{k}=10^{-6} \mathrm{cgs}\right)\end{array}$ \\
\hline 15.75 & 382.20 & 1.7 \\
\hline 15.80 & 383.70 & 1.7 \\
\hline 15.85 & 385.20 & 1.9 \\
\hline 15.90 & 386.70 & 2.1 \\
\hline 15.95 & 388.20 & 1.9 \\
\hline 16.00 & 389.70 & 1.9 \\
\hline 16.05 & 391.20 & 2.4 \\
\hline 16.10 & 392.70 & 2.7 \\
\hline 16.15 & 394.20 & 2.9 \\
\hline 16.20 & 395.70 & 2.1 \\
\hline 16.25 & 397.20 & 1.5 \\
\hline 16.30 & 398.70 & 1.1 \\
\hline 16.35 & 400.20 & 0.9 \\
\hline 16.40 & 401.70 & 1.1 \\
\hline 16.45 & 403.20 & 1.1 \\
\hline 16.50 & 404.70 & 0.9 \\
\hline 16.55 & 408.60 & 1.1 \\
\hline 16.65 & 417.60 & 1.5 \\
\hline 16.70 & 422.10 & 1.5 \\
\hline 16.75 & 423.70 & 1.6 \\
\hline 16.80 & 424.60 & 1.9 \\
\hline 16.85 & 425.60 & 2.3 \\
\hline 16.90 & 426.50 & 2.6 \\
\hline 16.95 & 427.40 & 3.6 \\
\hline 17.00 & 428.30 & 4.0 \\
\hline 17.05 & 429.20 & 4.4 \\
\hline 17.10 & 430.10 & 4.9 \\
\hline 17.15 & 431.10 & 4.6 \\
\hline 17.20 & 432.00 & 4.9 \\
\hline 17.25 & 432.90 & 4.6 \\
\hline 17.30 & 433.80 & 4.1 \\
\hline 17.35 & 434.90 & 3.7 \\
\hline 17.40 & 436.00 & 3.1 \\
\hline 17.45 & 437.10 & 3.0 \\
\hline 17.50 & 438.30 & 3.1 \\
\hline 17.55 & 439.40 & 3.0 \\
\hline 17.60 & 440.50 & 3.4 \\
\hline 17.65 & 441.60 & 3.9 \\
\hline 17.70 & 442.80 & 4.4 \\
\hline 17.75 & 443.90 & 3.9 \\
\hline 17.80 & 445.00 & 4.0 \\
\hline 17.85 & 446.20 & 3.4 \\
\hline 17.90 & 447.30 & 3.0 \\
\hline 17.95 & 448.40 & 2.8 \\
\hline 18.00 & 449.50 & 2.7 \\
\hline 18.05 & 450.70 & 2.4 \\
\hline 18.15 & 452.90 & 3.0 \\
\hline 18.20 & 454.00 & 2.9 \\
\hline 18.25 & 455.10 & 2.9 \\
\hline 18.30 & 456.30 & 2.7 \\
\hline 18.35 & 457.40 & 2.6 \\
\hline 18.40 & 458.50 & 2.7 \\
\hline 18.45 & 459.60 & 2.7 \\
\hline 18.50 & 460.80 & 3.2 \\
\hline 18.55 & 462.00 & 3.2 \\
\hline 18.60 & 463.20 & 3.4 \\
\hline 18.65 & 464.50 & 3.5 \\
\hline 18.70 & 465.70 & 3.5 \\
\hline 18.75 & 467.00 & 4.0 \\
\hline 18.80 & 468.20 & 4.0 \\
\hline 18.85 & 469.50 & 3.1 \\
\hline 18.90 & 470.70 & 2.6 \\
\hline 18.95 & 472.30 & 2.5 \\
\hline 19.00 & 474.00 & 2.3 \\
\hline 19.05 & 475.70 & 1.9 \\
\hline 19.10 & 477.30 & 2.5 \\
\hline 19.15 & 479.00 & 3.2 \\
\hline 19.20 & 480.70 & 3.2 \\
\hline 19.25 & 482.30 & 3.3 \\
\hline 19.30 & 484.00 & 2.7 \\
\hline 19.35 & 485.70 & 2.5 \\
\hline 19.40 & 487.30 & 2.4 \\
\hline 19.45 & 489.00 & 2.3 \\
\hline 19.50 & 490.70 & 2.1 \\
\hline 19.55 & 493.20 & 2.5 \\
\hline 19.65 & 498.70 & 3.5 \\
\hline 19.70 & 501.40 & 3.0 \\
\hline
\end{tabular}

Table 3 (continued).

\begin{tabular}{|c|c|c|}
\hline $\begin{array}{l}\text { Depth } \\
\text { in core } \\
\text { (m) }\end{array}$ & $\begin{array}{c}\text { Age } \\
\text { (k.y.B.P.) }\end{array}$ & $\begin{array}{l}\text { Volume magnetic } \\
\text { susceptibility } \\
\left(\mathrm{k}=10^{-6} \mathrm{cgs}\right)\end{array}$ \\
\hline 19.75 & 504.20 & 2.8 \\
\hline 19.80 & 506.90 & 3.4 \\
\hline 19.85 & 509.70 & 4.1 \\
\hline 19.90 & 512.40 & 4.4 \\
\hline 19.95 & 513.90 & 4.3 \\
\hline 20.00 & 515.00 & 4.1 \\
\hline 20.05 & 516.10 & 3.4 \\
\hline 20.10 & 517.20 & 3.3 \\
\hline 20.15 & 518.30 & 3.3 \\
\hline 20.20 & 519.40 & 3.0 \\
\hline 20.25 & 520.50 & 3.2 \\
\hline 20.30 & 521.60 & 3.0 \\
\hline 20.35 & 522.70 & 2.6 \\
\hline 20.40 & 523.80 & 2.4 \\
\hline 20.45 & 525.90 & 2.6 \\
\hline 20.50 & 528.20 & 2.9 \\
\hline 20.55 & 530.50 & 2.6 \\
\hline 20.60 & 532.90 & 2.3 \\
\hline 20.65 & 535.20 & 2.2 \\
\hline 20.70 & 537.50 & 2.4 \\
\hline 20.75 & 540.80 & 2.4 \\
\hline 20.80 & 544.30 & 2.9 \\
\hline 20.85 & 547.80 & 3.4 \\
\hline 20.90 & 551.30 & 3.4 \\
\hline 20.95 & 554.20 & 3.2 \\
\hline 21.00 & 556.90 & 3.5 \\
\hline 21.05 & 559.70 & 2.9 \\
\hline 21.15 & 565.20 & 3.8 \\
\hline 21.20 & 567.90 & 4.3 \\
\hline 21.25 & 570.70 & 4.3 \\
\hline 21.30 & 573.50 & 4.3 \\
\hline 21.35 & 576.20 & 4.4 \\
\hline 21.40 & 578.90 & 4.2 \\
\hline 21.45 & 581.70 & 4.3 \\
\hline 21.50 & 584.40 & 4.3 \\
\hline 21.55 & 587.20 & 3.3 \\
\hline 21.60 & 589.90 & 2.6 \\
\hline 21.65 & 592.70 & 2.4 \\
\hline 21.70 & 595.40 & 2.2 \\
\hline 21.75 & 597.00 & 2.3 \\
\hline 21.80 & 598.40 & 3.9 \\
\hline 21.85 & 599.70 & 4.2 \\
\hline 21.90 & 601.00 & 4.1 \\
\hline 21.95 & 602.30 & 3.5 \\
\hline 22.00 & 603.60 & 4.0 \\
\hline 22.05 & 604.90 & 4.3 \\
\hline 22.10 & 606.20 & 3.8 \\
\hline 22.15 & 607.50 & 3.5 \\
\hline 22.20 & 608.90 & 3.5 \\
\hline 22.25 & 610.20 & 3.5 \\
\hline 22.30 & 611.50 & 3.6 \\
\hline 22.35 & 612.80 & 2.9 \\
\hline 22.40 & 614.10 & 2.8 \\
\hline 22.45 & 615.40 & 2.8 \\
\hline 22.50 & 616.70 & 2.6 \\
\hline 22.55 & 618.10 & 3.7 \\
\hline 22.65 & 620.80 & 3.2 \\
\hline 22.70 & 622.20 & 3.4 \\
\hline 22.75 & 623.60 & 5.2 \\
\hline 22.80 & 625.00 & 5.4 \\
\hline 22.85 & 626.40 & 5.5 \\
\hline 22.90 & 627.70 & 5.3 \\
\hline 22.95 & 628.80 & 5.2 \\
\hline 23.00 & 629.80 & 5.3 \\
\hline 23.05 & 630.80 & 5.0 \\
\hline 23.10 & 631.80 & 4.9 \\
\hline 23.15 & 632.80 & 5.0 \\
\hline 23.20 & 633.80 & 5.1 \\
\hline 23.25 & 634.80 & 5.0 \\
\hline 23.30 & 635.80 & 4.6 \\
\hline 23.35 & 636.80 & 4.6 \\
\hline 23.40 & 637.80 & 4.8 \\
\hline 23.45 & 638.80 & 4.7 \\
\hline 23.50 & 639.80 & 4.8 \\
\hline 23.55 & 640.80 & 4.2 \\
\hline 23.60 & 641.80 & 4.0 \\
\hline 23.65 & 642.80 & 4.4 \\
\hline
\end{tabular}


S. C. CLEMENS, W. L. PRELL

Table 3 (continued).

\begin{tabular}{|c|c|c|}
\hline $\begin{array}{l}\text { Depth } \\
\text { in core } \\
\text { (m) }\end{array}$ & $\begin{array}{c}\text { Age } \\
\text { (k.y.B.P.) }\end{array}$ & $\begin{array}{l}\text { Volume magnetic } \\
\text { susceptibility } \\
\left(\mathrm{k}=10^{-6} \mathrm{cgs}\right)\end{array}$ \\
\hline 23.70 & 643.80 & 4.5 \\
\hline 23.75 & 644.80 & 4.9 \\
\hline 23.80 & 645.80 & 4.6 \\
\hline 23.85 & 646.80 & 4.3 \\
\hline 23.90 & 647.80 & 4.5 \\
\hline 23.95 & 648.80 & 5.1 \\
\hline 24.00 & 649.80 & 5.4 \\
\hline 24.05 & 650.80 & 5.2 \\
\hline 24.15 & 652.80 & 4.7 \\
\hline 24.20 & 653.80 & 5.3 \\
\hline 24.25 & 654.80 & 5.5 \\
\hline 24.30 & 655.80 & 5.6 \\
\hline 24.35 & 657.30 & 6.3 \\
\hline 24.40 & 659.00 & 6.5 \\
\hline 24.45 & 660.60 & 5.9 \\
\hline 24.50 & 662.30 & 5.1 \\
\hline 24.55 & 663.90 & 5.0 \\
\hline 24.60 & 665.60 & 5.2 \\
\hline 24.65 & 667.20 & 4.8 \\
\hline 24.70 & 668.90 & 5.2 \\
\hline 24.75 & 670.50 & 4.2 \\
\hline 24.80 & 672.20 & 5.4 \\
\hline 24.85 & 673.80 & 3.2 \\
\hline 24.90 & 675.50 & 2.9 \\
\hline 24.95 & 677.10 & 2.1 \\
\hline 25.00 & 678.80 & 1.6 \\
\hline 25.05 & 680.40 & 1.6 \\
\hline 25.10 & 682.10 & 1.6 \\
\hline 25.15 & 683.70 & 1.6 \\
\hline 25.20 & 685.40 & 1.1 \\
\hline 25.25 & 687.00 & 0.8 \\
\hline 25.30 & 688.70 & 0.8 \\
\hline 25.35 & 689.70 & 0.9 \\
\hline 25.40 & 690.60 & 1.1 \\
\hline 25.45 & 691.60 & 1.0 \\
\hline 25.50 & 692.50 & 1.5 \\
\hline 25.55 & 693.40 & 2.5 \\
\hline 25.60 & 694.30 & 3.2 \\
\hline 25.65 & 695.20 & 3.5 \\
\hline 25.70 & 696.10 & 4.3 \\
\hline 25.75 & 697.10 & 5.1 \\
\hline 25.80 & 698.00 & 5.3 \\
\hline 25.85 & 698.90 & 5.6 \\
\hline 25.90 & 699.80 & 5.7 \\
\hline 25.95 & 700.70 & 5.8 \\
\hline 26.00 & 701.60 & 5.8 \\
\hline 26.05 & 702.40 & 5.2 \\
\hline 26.10 & 703.30 & 3.8 \\
\hline 26.15 & 704.20 & 2.3 \\
\hline 26.25 & 705.90 & 2.8 \\
\hline 26.30 & 706.80 & 2.7 \\
\hline 26.35 & 707.70 & 2.4 \\
\hline 26.40 & 708.60 & 2.2 \\
\hline 26.45 & 709.40 & 2.1 \\
\hline 26.50 & 710.30 & 1.8 \\
\hline 26.55 & 711.20 & 1.9 \\
\hline 26.60 & 712.10 & 1.4 \\
\hline 26.65 & 712.90 & 1.4 \\
\hline 26.70 & 713.80 & 1.6 \\
\hline 26.75 & 714.70 & 1.8 \\
\hline 26.80 & 715.60 & 2.4 \\
\hline 26.85 & 716.40 & 3.5 \\
\hline 26.90 & 717.30 & 4.0 \\
\hline 26.95 & 718.20 & 4.0 \\
\hline 27.00 & 719.10 & 3.0 \\
\hline 27.05 & 719.90 & 1.8 \\
\hline 27.10 & 720.80 & 1.7 \\
\hline 27.15 & 721.60 & 2.0 \\
\hline 27.20 & 722.30 & 1.7 \\
\hline 27.25 & 723.00 & 1.6 \\
\hline 27.30 & 723.70 & 1.8 \\
\hline 27.35 & 724.40 & 2.1 \\
\hline 27.40 & 725.10 & 2.0 \\
\hline 27.45 & 725.90 & 2.2 \\
\hline 27.50 & 726.60 & 2.2 \\
\hline 27.55 & 727.30 & 1.7 \\
\hline 27.60 & 728.00 & 1.7 \\
\hline
\end{tabular}

Table 3 (continued).

\begin{tabular}{|c|c|c|}
\hline $\begin{array}{l}\text { Depth } \\
\text { in core } \\
(\mathrm{m})\end{array}$ & $\begin{array}{c}\text { Age } \\
\text { (k.y.B.P.) }\end{array}$ & $\begin{array}{l}\text { Volume magnetic } \\
\text { susceptibility } \\
\left(\mathrm{k}=10^{-6} \mathrm{cgs}\right)\end{array}$ \\
\hline 27.65 & 728.70 & 1.5 \\
\hline 27.75 & 730.10 & 3.2 \\
\hline 27.80 & 730.90 & 3.3 \\
\hline 27.85 & 732.10 & 3.1 \\
\hline 27.90 & 733.50 & 2.8 \\
\hline 27.95 & 734.90 & 2.3 \\
\hline 28.00 & 736.30 & 2.2 \\
\hline 28.05 & 737.70 & 2.2 \\
\hline 28.10 & 739.10 & 2.6 \\
\hline 28.15 & 740.40 & 3.2 \\
\hline 28.20 & 741.80 & 4.0 \\
\hline 28.25 & 743.20 & 4.4 \\
\hline 28.30 & 744.60 & 4.9 \\
\hline 28.35 & 746.00 & 4.9 \\
\hline 28.40 & 747.40 & 4.8 \\
\hline 28.45 & 748.80 & 4.7 \\
\hline 28.50 & 750.20 & 4.6 \\
\hline 28.55 & 751.60 & 4.8 \\
\hline 28.60 & 752.90 & 5.0 \\
\hline 28.65 & 754.30 & 4.5 \\
\hline 28.70 & 755.70 & 4.1 \\
\hline 28.75 & 756.70 & 4.2 \\
\hline 28.80 & 757.50 & 4.1 \\
\hline 28.85 & 758.40 & 4.2 \\
\hline 28.90 & 759.20 & 4.0 \\
\hline 28.95 & 760.10 & 3.8 \\
\hline 29.00 & 761.00 & 3.2 \\
\hline 29.05 & 761.80 & 2.7 \\
\hline 29.10 & 762.70 & 2.7 \\
\hline 29.15 & 763.50 & 2.8 \\
\hline 29.25 & 765.20 & 3.0 \\
\hline 29.30 & 766.10 & 2.5 \\
\hline 29.35 & 766.90 & 2.1 \\
\hline 29.40 & 767.80 & 1.8 \\
\hline 29.45 & 768.60 & 1.8 \\
\hline 29.50 & 769.50 & 2.0 \\
\hline 29.55 & 770.30 & 2.2 \\
\hline 29.60 & 771.20 & 2.3 \\
\hline 29.65 & 772.10 & 2.1 \\
\hline 29.70 & 772.90 & 1.7 \\
\hline 29.75 & 773.80 & 1.8 \\
\hline 29.80 & 774.60 & 2.6 \\
\hline 29.85 & 775.50 & 3.5 \\
\hline 29.90 & 776.30 & 2.8 \\
\hline 29.95 & 777.20 & 2.2 \\
\hline 30.00 & 778.00 & 2.1 \\
\hline 30.05 & 778.90 & 2.4 \\
\hline 30.10 & 779.70 & 1.7 \\
\hline 30.15 & 780.60 & 1.4 \\
\hline 30.20 & 781.50 & 1.6 \\
\hline 30.25 & 782.30 & 1.9 \\
\hline 30.30 & 783.20 & 2.3 \\
\hline 30.35 & 784.00 & 2.8 \\
\hline 30.40 & 784.90 & 2.4 \\
\hline 30.45 & 785.70 & 2.4 \\
\hline 30.50 & 786.60 & 2.1 \\
\hline 30.55 & 787.40 & 1.9 \\
\hline 30.60 & 788.30 & 1.7 \\
\hline 30.65 & 789.10 & 1.6 \\
\hline 30.75 & 790.80 & 3.8 \\
\hline 30.80 & 791.70 & 4.7 \\
\hline 30.85 & 792.60 & 5.2 \\
\hline 30.90 & 793.40 & 5.3 \\
\hline 30.95 & 794.30 & 5.6 \\
\hline 31.00 & 795.10 & 6.0 \\
\hline 31.05 & 796.00 & 6.0 \\
\hline 31.10 & 796.80 & 6.0 \\
\hline 31.15 & 797.50 & 5.2 \\
\hline 31.20 & 798.20 & 4.9 \\
\hline 31.25 & 798.80 & 5.3 \\
\hline 31.30 & 799.40 & 5.5 \\
\hline 31.35 & 800.10 & 5.5 \\
\hline 31.40 & 800.70 & 5.3 \\
\hline 31.45 & 801.40 & 5.2 \\
\hline 31.50 & 802.00 & 4.8 \\
\hline 31.55 & 802.60 & 4.7 \\
\hline 31.60 & 803.30 & 4.8 \\
\hline
\end{tabular}


Table 3 (continued).

\begin{tabular}{|c|c|c|}
\hline $\begin{array}{l}\text { Depth } \\
\text { in core } \\
\text { (m) }\end{array}$ & $\begin{array}{c}\text { Age } \\
\text { (k.y.B.P.) }\end{array}$ & $\begin{array}{l}\text { Volume magnetic } \\
\text { susceptibility } \\
\left(\mathrm{k}=10^{-6} \mathrm{cgs}\right)\end{array}$ \\
\hline 31.65 & 803.90 & 4.4 \\
\hline 31.70 & 804.60 & 5.0 \\
\hline 31.75 & 805.20 & 5.8 \\
\hline 31.80 & 805.80 & 6.5 \\
\hline 31.85 & 806.50 & 6.5 \\
\hline 31.90 & 807.10 & 6.3 \\
\hline 31.95 & 807.80 & 6.2 \\
\hline 32.00 & 808.40 & 6.2 \\
\hline 32.05 & 809.00 & 6.1 \\
\hline 32.10 & 809.70 & 6.4 \\
\hline 32.15 & 810.30 & 6.5 \\
\hline 32.25 & 811.60 & 5.2 \\
\hline 32.30 & 812.20 & 5.0 \\
\hline 32.35 & 812.90 & 4.4 \\
\hline 32.40 & 813.50 & 3.7 \\
\hline 32.45 & 814.20 & 2.9 \\
\hline 32.50 & 814.80 & 2.4 \\
\hline 32.55 & 815.40 & 2.5 \\
\hline 32.60 & 816.10 & 3.0 \\
\hline 32.65 & 816.70 & 3.5 \\
\hline 32.70 & 817.40 & 3.2 \\
\hline 32.75 & 819.70 & 3.0 \\
\hline 32.80 & 822.50 & 3.3 \\
\hline 32.85 & 825.30 & 3.8 \\
\hline 32.90 & 828.10 & 4.7 \\
\hline 32.95 & 830.90 & 6.4 \\
\hline 33.00 & 833.70 & 7.0 \\
\hline 33.05 & 836.50 & 7.2 \\
\hline 33.10 & 839.30 & 7.5 \\
\hline 33.15 & 840.70 & 6.9 \\
\hline 33.20 & 841.70 & 6.1 \\
\hline 33.25 & 842.70 & 6.0 \\
\hline 33.30 & 843.70 & 6.0 \\
\hline 33.35 & 844.70 & 6.2 \\
\hline 33.40 & 845.70 & 6.6 \\
\hline 33.45 & 846.70 & 6.1 \\
\hline 33.50 & 847.70 & 6.4 \\
\hline 33.55 & 848.70 & 6.1 \\
\hline 33.60 & 849.70 & 5.5 \\
\hline 33.65 & 850.70 & 5.8 \\
\hline 33.75 & 852.70 & 5.8 \\
\hline 33.80 & 853.70 & 5.3 \\
\hline 33.85 & 854.70 & 5.8 \\
\hline 33.90 & 855.70 & 5.9 \\
\hline 33.95 & 856.70 & 5.5 \\
\hline 34.00 & 857.70 & 5.4 \\
\hline 34.05 & 858.70 & 5.6 \\
\hline 34.10 & 859.70 & 5.2 \\
\hline 34.15 & 860.70 & 5.2 \\
\hline 34.20 & 861.70 & 5.7 \\
\hline 34.25 & 863.00 & 6.2 \\
\hline 34.30 & 864.40 & 5.7 \\
\hline 34.35 & 865.80 & 4.7 \\
\hline 34.45 & 868.60 & 3.5 \\
\hline 34.50 & 870.00 & 3.5 \\
\hline 34.55 & 871.40 & 3.3 \\
\hline 34.60 & 872.80 & 2.6 \\
\hline 34.65 & 874.20 & 3.7 \\
\hline 34.70 & 875.50 & 5.0 \\
\hline 34.75 & 876.90 & 5.0 \\
\hline 34.80 & 878.30 & 5.4 \\
\hline 34.85 & 879.70 & 5.5 \\
\hline 34.90 & 881.10 & 5.5 \\
\hline 34.95 & 882.00 & 5.3 \\
\hline 35.00 & 882.80 & 4.7 \\
\hline 35.05 & 883.50 & 4.2 \\
\hline 35.10 & 884.30 & 3.9 \\
\hline 35.15 & 885.00 & 3.8 \\
\hline 35.20 & 885.80 & 4.0 \\
\hline 35.25 & 886.50 & 4.2 \\
\hline 35.30 & 887.30 & 3.6 \\
\hline 35.35 & 888.00 & 3.3 \\
\hline 35.40 & 888.80 & 3.5 \\
\hline 35.45 & 889.50 & 4.0 \\
\hline 35.50 & 890.30 & 3.4 \\
\hline 35.55 & 891.10 & 1.8 \\
\hline 35.60 & 891.80 & 1.2 \\
\hline
\end{tabular}

Table 3 (continued).

\begin{tabular}{|c|c|c|}
\hline $\begin{array}{l}\text { Depth } \\
\text { in core } \\
(\mathrm{m})\end{array}$ & $\begin{array}{c}\text { Age } \\
\text { (k.y.B.P.) }\end{array}$ & $\begin{array}{l}\text { Volume magnetic } \\
\text { susceptibility } \\
\left(\mathrm{k}=10^{-6} \mathrm{cgs}\right)\end{array}$ \\
\hline 35.65 & 892.60 & 2.1 \\
\hline 35.70 & 893.30 & 2.6 \\
\hline 35.75 & 894.10 & 3.1 \\
\hline 35.85 & 895.60 & 4.1 \\
\hline 35.90 & 896.30 & 3.2 \\
\hline 35.95 & 897.10 & 2.9 \\
\hline 36.00 & 897.80 & 3.6 \\
\hline 36.05 & 898.60 & 3.6 \\
\hline 36.10 & 899.30 & 3.9 \\
\hline 36.15 & 900.50 & 3.8 \\
\hline 36.20 & 901.70 & 3.2 \\
\hline 36.25 & 902.90 & 3.0 \\
\hline 36.30 & 904.10 & 2.8 \\
\hline 36.35 & 905.40 & 2.1 \\
\hline 36.40 & 906.60 & 1.4 \\
\hline 36.45 & 907.80 & 1.0 \\
\hline 36.50 & 909.00 & 0.8 \\
\hline 36.55 & 910.30 & 1.1 \\
\hline 36.60 & 911.50 & 1.3 \\
\hline 36.65 & 912.70 & 2.2 \\
\hline 36.70 & 913.90 & 3.7 \\
\hline 36.75 & 915.10 & 4.2 \\
\hline 36.80 & 916.40 & 4.5 \\
\hline 36.85 & 917.60 & 4.5 \\
\hline 36.90 & 918.80 & 4.0 \\
\hline 36.95 & 920.00 & 4.4 \\
\hline 37.00 & 921.30 & 3.8 \\
\hline 37.05 & 923.00 & 3.5 \\
\hline 37.10 & 924.90 & 2.9 \\
\hline 37.15 & 926.80 & 2.9 \\
\hline 37.20 & 928.60 & 3.1 \\
\hline 37.25 & 930.50 & 3.8 \\
\hline 37.35 & 934.30 & 4.6 \\
\hline 37.40 & 936.20 & 4.5 \\
\hline 37.45 & 938.00 & 3.6 \\
\hline 37.50 & 939.90 & 3.5 \\
\hline 37.55 & 941.80 & 3.9 \\
\hline 37.60 & 943.70 & 3.2 \\
\hline 37.65 & 945.50 & 3.1 \\
\hline 37.70 & 947.40 & 3.4 \\
\hline 37.75 & 949.10 & 3.3 \\
\hline 37.80 & 950.70 & 2.9 \\
\hline 37.85 & 952.30 & 3.1 \\
\hline 37.90 & 954.00 & 3.2 \\
\hline 37.95 & 955.60 & 3.3 \\
\hline 38.00 & 957.20 & 3.2 \\
\hline 38.05 & 958.80 & 2.6 \\
\hline 38.10 & 960.40 & 2.4 \\
\hline 38.15 & 962.10 & 2.6 \\
\hline 38.20 & 963.70 & 3.3 \\
\hline 38.25 & 965.30 & 4.0 \\
\hline 38.30 & 966.90 & 4.5 \\
\hline 38.35 & 968.60 & 4.9 \\
\hline 38.40 & 970.20 & 4.8 \\
\hline 38.45 & 971.50 & 5.0 \\
\hline 38.50 & 972.80 & 5.5 \\
\hline 38.55 & 974.10 & 5.6 \\
\hline 38.60 & 975.40 & 6.0 \\
\hline 38.65 & 976.60 & 6.1 \\
\hline 38.70 & 977.90 & 6.7 \\
\hline 38.75 & 979.20 & 7.3 \\
\hline 38.85 & 981.80 & 5.6 \\
\hline 38.90 & 983.00 & 4.4 \\
\hline 38.95 & 984.30 & 3.1 \\
\hline 39.00 & 985.60 & 2.2 \\
\hline 39.05 & 986.90 & 2.0 \\
\hline 39.10 & 988.10 & 2.3 \\
\hline 39.15 & 988.80 & 3.3 \\
\hline 39.20 & 989.40 & 3.9 \\
\hline 39.25 & 990.00 & 3.9 \\
\hline 39.30 & 990.50 & 3.4 \\
\hline 39.35 & 991.10 & 3.0 \\
\hline 39.40 & 991.60 & 2.8 \\
\hline 39.45 & 992.20 & 2.4 \\
\hline 39.50 & 992.70 & 2.7 \\
\hline 39.55 & 993.30 & 3.9 \\
\hline 39.60 & 993.90 & 4.1 \\
\hline
\end{tabular}


Table 3 (continued).

\begin{tabular}{ccc}
\hline $\begin{array}{c}\text { Depth } \\
\text { in core } \\
(\mathrm{m})\end{array}$ & $\begin{array}{c}\text { Age } \\
\text { (k.y.B.P.) }\end{array}$ & $\begin{array}{c}\text { Volume magnetic } \\
\text { susceptibility } \\
\left(\mathrm{k}=10^{-6} \text { cgs }\right)\end{array}$ \\
\hline 39.65 & 994.40 & 4.5 \\
39.70 & 995.00 & 4.9 \\
39.75 & 995.50 & 4.9 \\
39.80 & 996.10 & 4.9 \\
39.85 & 996.60 & 4.6 \\
39.90 & 997.20 & 4.6 \\
39.95 & 997.80 & 4.0 \\
40.00 & 998.30 & 3.5 \\
\hline
\end{tabular}

centration of magnetically susceptible minerals and increased concentration of lithogenic material in Owen Ridge sediments.

\section{Discussion}

The volume magnetic susceptibility record from the Owen Ridge is clearly an excellent proxy for the lithogenic percent. This finding indicates that the ferrimagnetic minerals responsible for the signal are terrestrial in origin and wind-transported to the Owen Ridge. Similar to other concentration measurements, the magnetic susceptibility record is subject to dilution by nonmagnetic components such as biogenic opal and carbonate, and cannot be considered a lithogenic MAR signal. However, given the excellent correlation between the lithogenic percent and magnetic susceptibility, a simple regression equation (Fig. 6A) can be derived to convert magnetic susceptibility to lithogenic concentration. Multiplication of the converted record by the linear sedimentation rate and the dry bulk density would then provide a high resolution MAR record which can be used as a proxy for past changes in source-area aridity.

\section{Grain-Size Record: Combination Frequencies and Interocean Coherence}

Unlike the weight percent, MAR, and magnetic susceptibility records, the grain-size record shows a distinct change in amplitude at 500 k.y. (Fig. 3). For the purpose of spectral analysis, we divided the grain-size record into two parts (6-500 k.y. and 500-954 k.y.) in order to avoid nonstationary changes in the frequency domain.

In addition to spectral peaks (concentrations of variance) associated with primary Milankovitch periods $(400,100,41,23$, and 19 k.y.), our analyses revealed a number of peaks which cannot be related directly to Milankovitch forcing (Fig. 7A, B). For the precessional peaks (19 and $23 \mathrm{k.y}$.), we understand some of the physical interactions between internal and external forcing mechanisms which determine the strength and timing of monsoon winds (see "Background and Previous Work" section; Clemens and Prell, 1990). However, the precessional peaks account for a relatively small, though important, portion of the total variance. Spectral peaks at non-primary Milankovitch periodicities account for a significant portion of the total variance but are not well understood. These peaks are, however, near those associated with combinations (cross-products) of the primary Milankovitch frequencies and may reflect nonlinear interactions within the climate system (Saltzman et al., 1984; Le Treut et al., 1988; Pestiaux et al., 1988; Pisias and Rea, 1988; Ghil, 1989).

The spectrum over the interval from 6 to 500 k.y. indicates power centered near 59,33 , and $28 \mathrm{k} . \mathrm{y}$. in addition to the primary Milankovitch frequencies near 400, 100, 23, and 19 k.y. (Fig. 7A). Over the interval from 500 to 954 k.y. there is an additional peak centered at 47.6 k.y. (Fig. 7B). The shorter periodicities ( $\leq \sim 17 \mathrm{k} . \mathrm{y}$.) approach the limit of our spectral resolution (Nyquist frequency). We thus hesitate to place confidence in these spectral peaks. The 33 and 28 k.y. periodicities are near the cross-product frequencies of precession and obliquity $(1 / 19$ $-1 / 41=1 / 35.4)$, precession and eccentricity $(1 / 23-1 / 100$ $=1 / 29.9)$, and eccentricity and obliquity $(1 / 100+1 / 41=1 /$ 29.1). The 59 k.y. peak encompasses power at 52 k.y. possibly associated with precession and obliquity $(1 / 23-1 / 41=1 /$ 52.4). The broad spectral peak centered on 47.6 encompasses power at both the $41 \mathrm{k} . \mathrm{y}$. obliquity band and the $52 \mathrm{k} . \mathrm{y}$. precession-obliquity cross-product $(1 / 23-1 / 41=1 / 52.4)$.

In addition to an association with combination frequencies of the primary Milankovitch bands, the $52 \mathrm{k} . \mathrm{y}$. period (within the peak centered on 59 k.y.) and 29 k.y. period are singled out (1) by the fact that direct insolation forcing associated with variations in the Earth's obliquity cycle occurs with periodicities of 54 and 29 k.y. (Berger, 1984) and (2) because similar periodicities have been found in eolian grain-size records from the central equatorial Pacific (Pisias and Rea, 1988).

Pisias and Rea (1988) found a strong 31 k.y. period in the grain-size record from RC11-210, a record used to monitor the strength of southeast trade winds in the equatorial Pacific. Variance within the $31 \mathrm{k} . \mathrm{y}$. spectral peak was shown to be coherent with the cross-product of eccentricity and obliquity $(1 / 100+$ $1 / 41=1 / 29.1$ ) over the interval from 402 to 774 k.y.; the younger interval of the core was excluded from the analysis due to uncertainty of the age model.

The Hole 722B grain-size record, of comparable length to RC11-210, allows for interocean comparison of wind-strength records. Coherence between these two records from opposite sides of the Earth would indicate a global link between the paleo-monsoon in the Indian Ocean and the paleotrade winds of the Pacific. We compare the Hole 722B and RC11-210 records over the interval from 500 to 774 k.y. in order to be consistent with the study published by Pisias and Rea (1988). We also compare the records over the interval from 6 to 248 k.y., an interval for which the initial age-model has been refined by carbonate correlation to a nearby core with a higher resolution age model

A Lithogenic percent $=12.355+4.9056$ (magnetic susceptibility) $R=0.91$

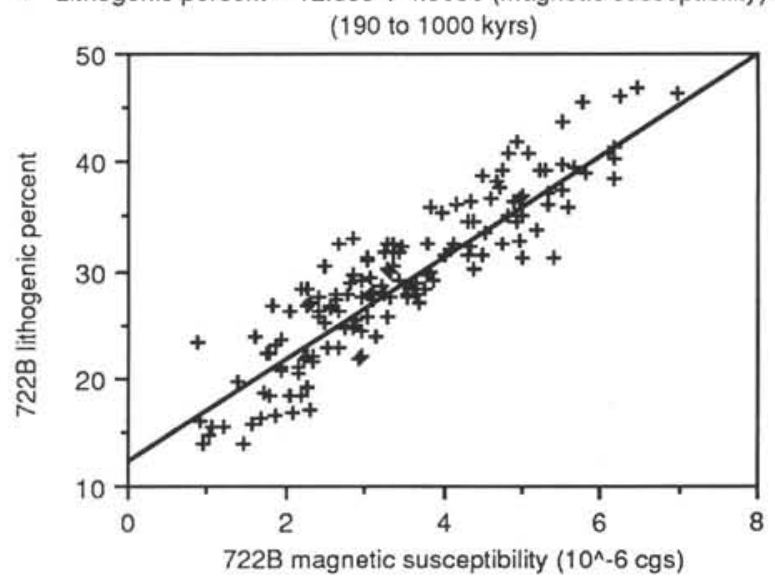

Figure 6. A. Linear regression of Hole 722B lithogenic percent and magnetic susceptibility indicating a strong $(R=0.91)$ positive relationship between the two records. B. (upper graph) Spectral density and cross coherency for Hole 722B lithogenic percent and volume magnetic susceptibility. Statistically significant coherence is demonstrated over the entire spectrum. Spectral densities are plotted on normalized log scales. The coherence spectrum ( $y$-axis, solid line with pluses) is plotted on a hyperbolic arctangent scale. The solid horizontal line indicates confidence at the $95 \%$ level. (bottom graph) Phase-angle vs. frequency plot: Zero phase is demonstrated for the entire spectrum. 

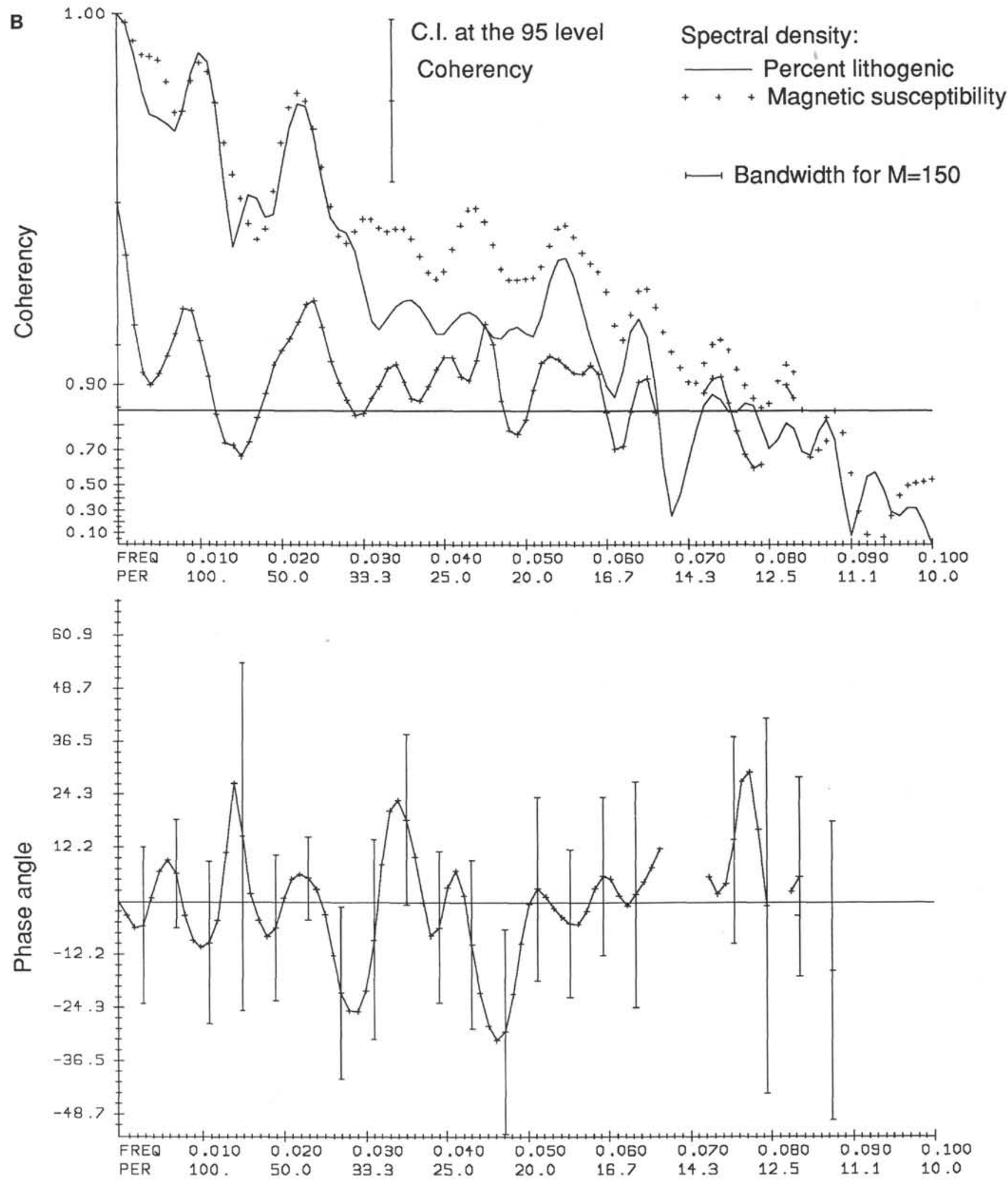

Hole 722B Weight percent lithogenic vs. magnetic susceptibility 190 to 954 kyrs Figure 6 (continued). 


\section{Confidence interval at the 80 level}
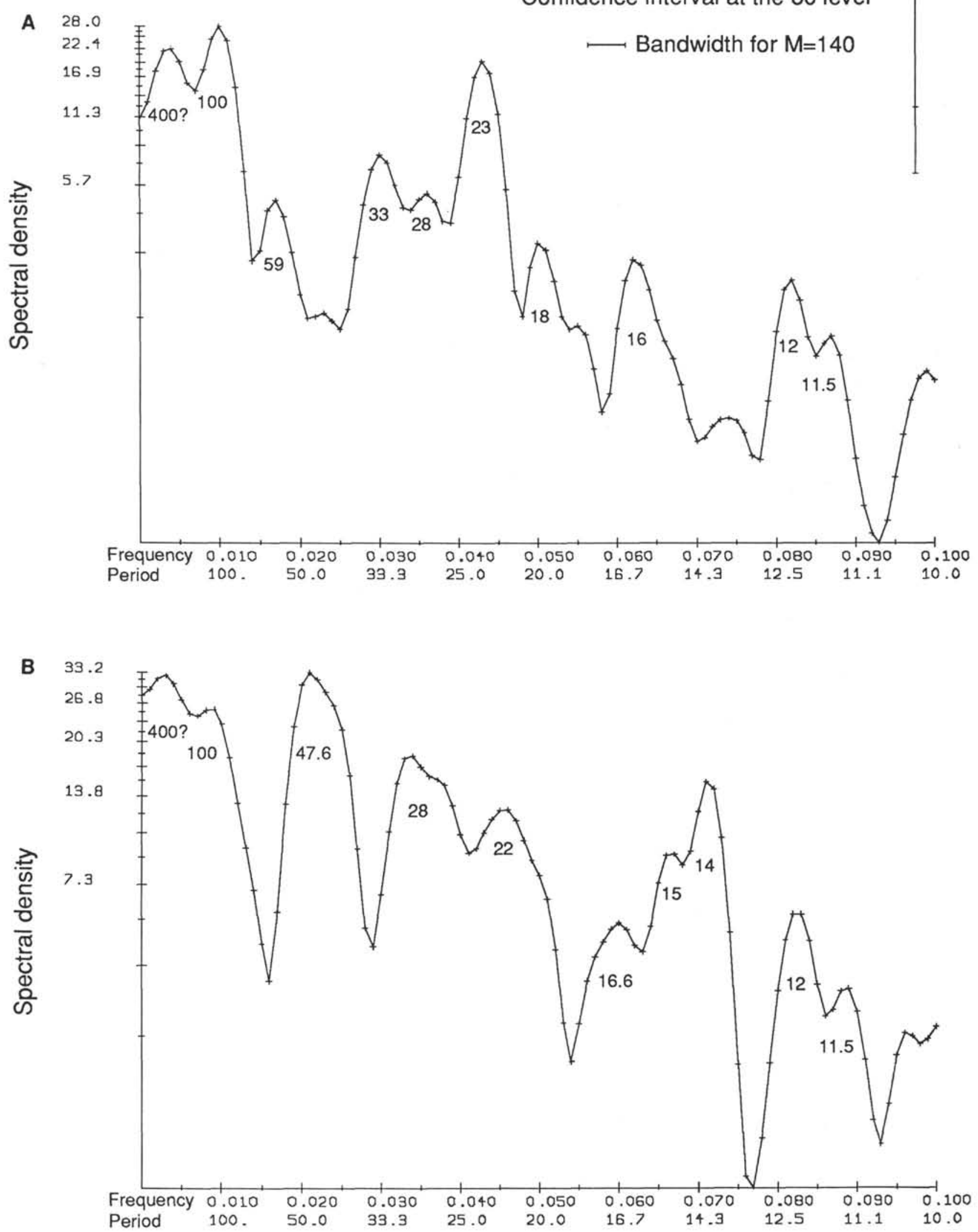

Figure 7. Spectral density (normalized log scale) of Hole 722B lithogenic grain size. A. Interval from 6 to 500 k.y. B. Interval from 500 to 954 k.y. Both intervals are characterized by a number of strong spectral peaks, some of which coincide with primary Milankovitch periods (400, $100,41,23$, and 19 k.y.) and some of which do not (see text for discussion). 
(W8402A-14GC) (Murray, in press). Over the 500-774 k.y. interval, weak, but significant, coherence and zero phase is demonstrated for the 29 k.y. periodicity (eccentricity-obliquity crossproduct). We note, however, that the coherence is not associated with clearly resolved spectral peaks (RC11-210, Fig. 8A). The 6248 k.y. comparison indicates that the records share strong coherence and a zero phase relationship for the $52 \mathrm{k}$.y. periodicity (precession-obliquity cross-product) though the peak in Hole 722B is relatively small compared to that of RC11-210 (Fig. 8B).

\section{Discussion}

\section{Interocean Coherence}

The coherence and zero phase relationships between grainsize records from the Arabian Sea and the central equatorial Pacific lend support to the hypothesis that the 52 and 29 k.y. periodicities are climatically meaningful features of both records. The coherence, however, for the 500 to 774 k.y. comparison is somewhat bandwidth-dependent and not associated with a clearly resolved peak in the RC11-210 record. However, our confidence is bolstered by (1) the zero phase relationship and small phase error, (2) the fact that $29 \mathrm{k}$.y. periodicity in both records is coherent with the eccentricity-obliquity cross-product (discussed below), and (3) the independence of the two age models which argues against the coherence being an artifact of the analysis. The same arguments bolster our confidence in the coherent relationship over the $52 \mathrm{k}$.y. period for the 6-248 k.y interval.

The modern Indian Ocean monsoon and Pacific trade winds are linked on the interannual scale via a wind anomaly which originates in the Indian Ocean and travels eastward across the equatorial Pacific, possessing characteristics similar to that of a Kelvin wave (Barnett, 1984a, b). This atmospheric anomaly exerts a strong influence on Pacific Ocean sea-surface temperature (SST) and appears to be sustained by the release of latent heat associated with a precipitation anomaly which travels with, and is phase-locked to the wind anomaly. Such observations are broadly consistent with our finding that the Pacific and Indian Ocean wind systems are coupled over geological time scales.

The inference of a global link between paleo-wind fields of the Pacific and Indian Oceans is a topic that should be explored in greater depth beginning with a detailed comparison of the respective age-models in order to identify and compensate for possible inconsistencies. Further comparisons, including faunal wind-strength indicators (the $G$. bulloides upwelling record from Hole $722 \mathrm{~B}$ and the divergent radiolarian assemblage from RC11210), will then help to answer the following questions: (1) do the faunal records of wind-strength also show interocean coherence?, and (2) will comparison of the faunal and lithogenic records help to isolate that portion of variance in the faunal records which is due to nutrient forcing from that which is due to direct wind forcing (e.g., intermediate to deep-water nutrient stratification)? A better understanding of these relationships will help define the nature of the physical link between the Pacific southeast trades and the Indian Ocean monsoon over late Pleistocene (Barnett, 1983, 1984a, b).

\section{Combination Frequencies}

As previously discussed, two possible origins for the 52 and 29 k.y. periodicities in the Hole 722B grain-size record include (1) direct forcing by the 54 and 29 k.y. components of obliquity and/or (2) nonlinear responses of the climate system to insolation forcing at the primary Milankovitch frequencies, resulting in cross-product, or combination frequencies. In terms of combination frequencies, the $52 \mathrm{k} . \mathrm{y}$. variance is near the cross-product of precession and obliquity $(1 / 23-1 / 41=1 / 52.4)$ while the variance at $29 \mathrm{k} . \mathrm{y}$. is near both the cross-products of preces- sion and eccentricity $(1 / 23-1 / 100=1 / 29.9)$ and eccentricity and obliquity $(1 / 100+1 / 41=1 / 29.1)$. Our analyses of these possibilities, for the same intervals over which we find coherence with the RC11-210 grain-size record, indicates low coherence with both the 54 and 29 k.y. component of obliquity (spectrum not shown). We do, however, find significant coherency with the precession-obliquity cross-product (52 k.y.; Fig. 9) and significant coherency with both cross-products yielding periodicities near 29 k.y., though the eccentricity-obliquity crossproduct is stronger (Fig. 10). We interpret these findings as indicating that the variance at 52 and 29 k.y. is not linearly related to direct insolation forcing but reflects nonlinear response of the monsoon system to insolation forcing associated with the primary Milankovitch bands.

Variance encompassed within the broad spectral peak centered on 47.6 k.y. spans periodicities from 37 to 62 k.y. (Fig. 7B). Preliminary analyses indicate significant coherence with the 41 k.y. obliquity cycle but also with the 52 k.y. precessionobliquity cross-product (spectra not shown). These findings indicate that the majority of variance within this peak is related to obliquity but not necessarily in a linear fashion.

Recent work using low-order, time-dependent, dynamic climate models to study climatic variations inferred from the marine oxygen isotope record has provided insight into the possible mechanisms responsible for combination frequencies found in deep-sea paleoclimate records (Saltzman et al., 1984; Le Treut et al., 1988; Ghil, 1989). Saltzman et al., (1984) employ equations accounting for the mass balance of continental ice-sheets (accumulation/ablation), marine ice-sheets, and mean ocean temperature (hydrological cycle). When externally forced by insolation changes due to the Earth's orbital variations, the model produces variability unaccounted for by either the insolation forcing or free oscillations due to internal feedback mechanisms within the model (e.g., Saltzman et al., 1984; Fig. 6) indicating a nonlinear interaction between the external forcing and internal climatic feedbacks.

Le Treut et al., (1988) model the coupled effects of global mean temperature, the extent of continental ice (accumulation/ ablation), and bedrock deflection under the ice-sheets in order to predict climatic oscillations in marine and ice-core oxygen isotope records. Their results indicate that ice-albedo feedback, temperature dependence of the hydrologic cycle, and bedrock deflection, are key internal climatic mechanisms to which the model response is highly nonlinear when forced by external (orbital) insolation variations.

Ghil (1989) differentiates between the terms "entrainment," "chaos," and "combination frequencies," in an orbitally forced model which includes radiation balance (ice-albedo feedback), ice mass balance (precipitation-temperature feedback), and isostatic rebound (bedrock deflection). Ghil finds that, in the absence of external forcing, the model oscillates with an internal periodicity of $10 \mathrm{k} . \mathrm{y}$. With small amounts of single-frequency orbital forcing applied to the model during its internal oscillation mode, Ghil finds a total transfer of variability from the internal periodicity ( $10 \mathrm{k} . \mathrm{y}$.) to the forcing frequency, a response he terms "entrainment." With increased strength of single-frequency external forcing, the power spectrum becomes continuous and the system is termed "chaotic." Finally, with multifrequency precessional forcing at both the 23 and 19 k.y. periodicities, the model produces "combination frequencies" similar to those found in high resolution paleoclimatic records from the deep sea.

These models share a general mechanism for production of combination frequencies. The combination frequencies are the result of interaction between external insolation forcing and some form of internal feedback mechanism within the climate sys- 
S. C. CLEMENS, W. L. PRELL

A Bandwidth for $M=80$
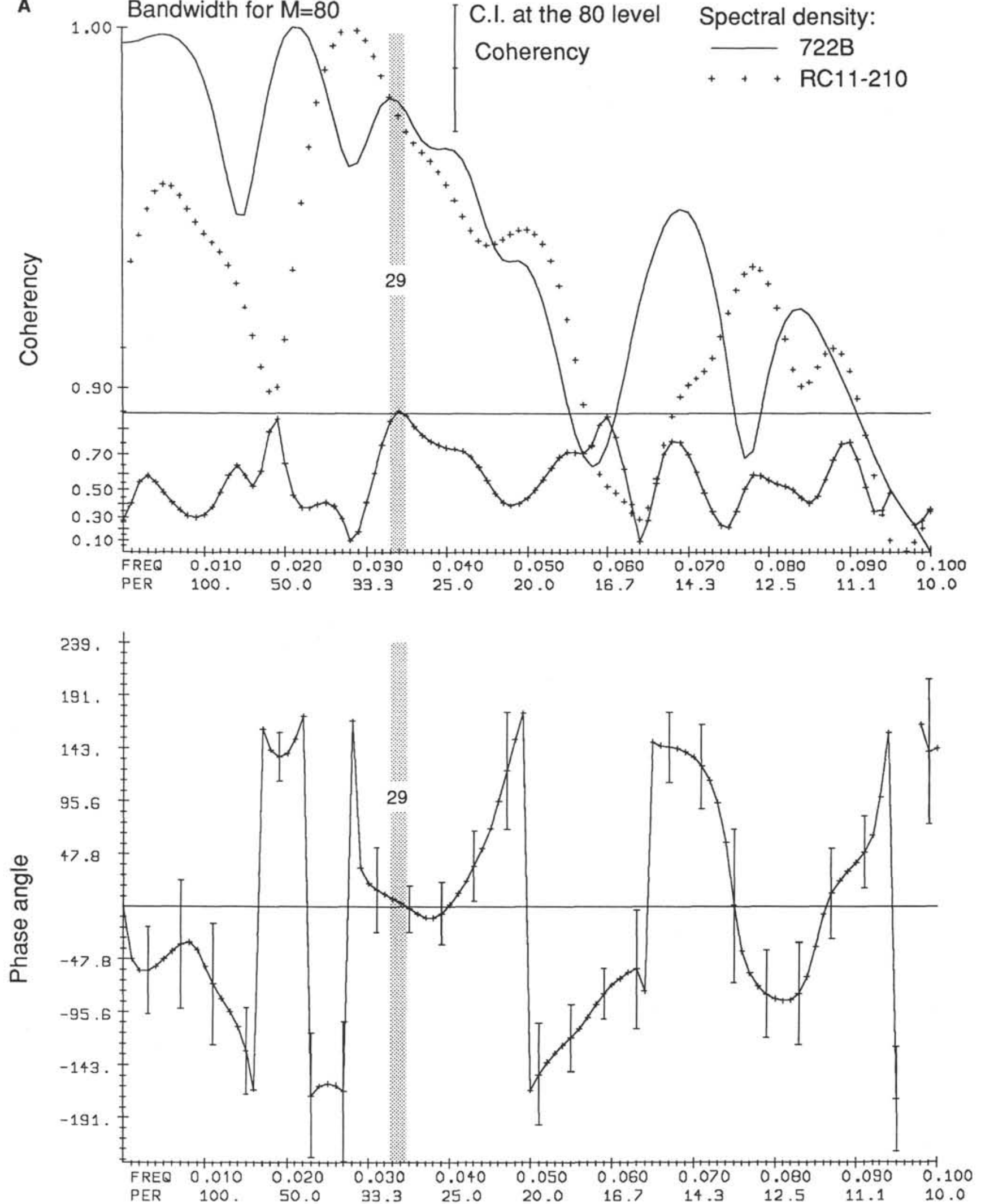

Figure 8. Spectral comparison (see Fig. 6B caption for plot details) between grain-size records from the Arabian Sea (Hole 722B; summer monsoon wind-strength index) and the central equatorial Pacific Ocean (RC11-210; southeast trades wind-strength index). Significant coherence and zero phase lag is demonstrated for (A) the 29 k.y. periodicity over the interval 500-774 k.y. and (B) the 52 k.y. periodicity over the interval 6248 k.y. The significant coherencies and zero phase relationships indicate a direct link between the paleo-strength of Pacific Ocean trade winds and Indian Ocean monsoons. 
B
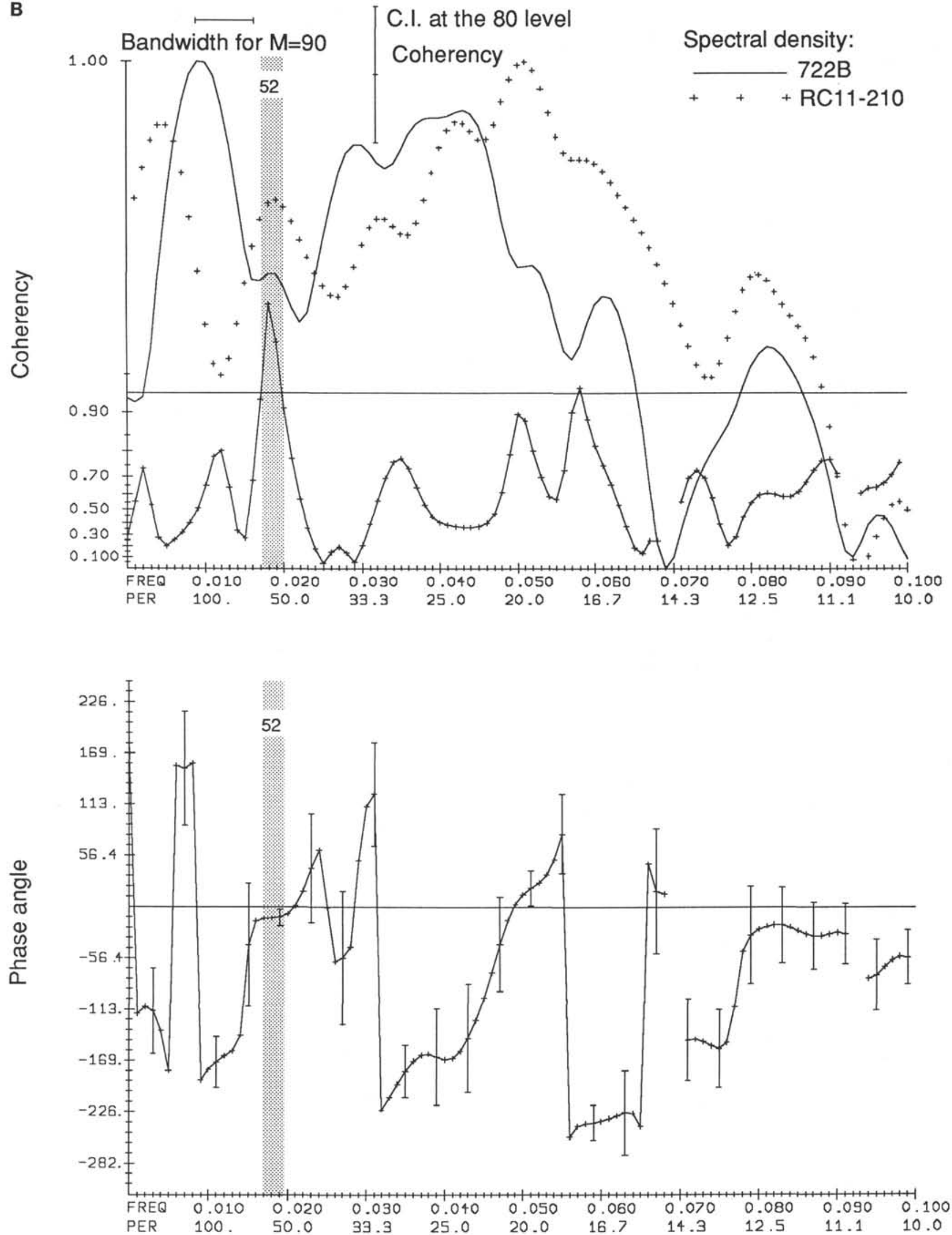

Figure 8 (continued). 


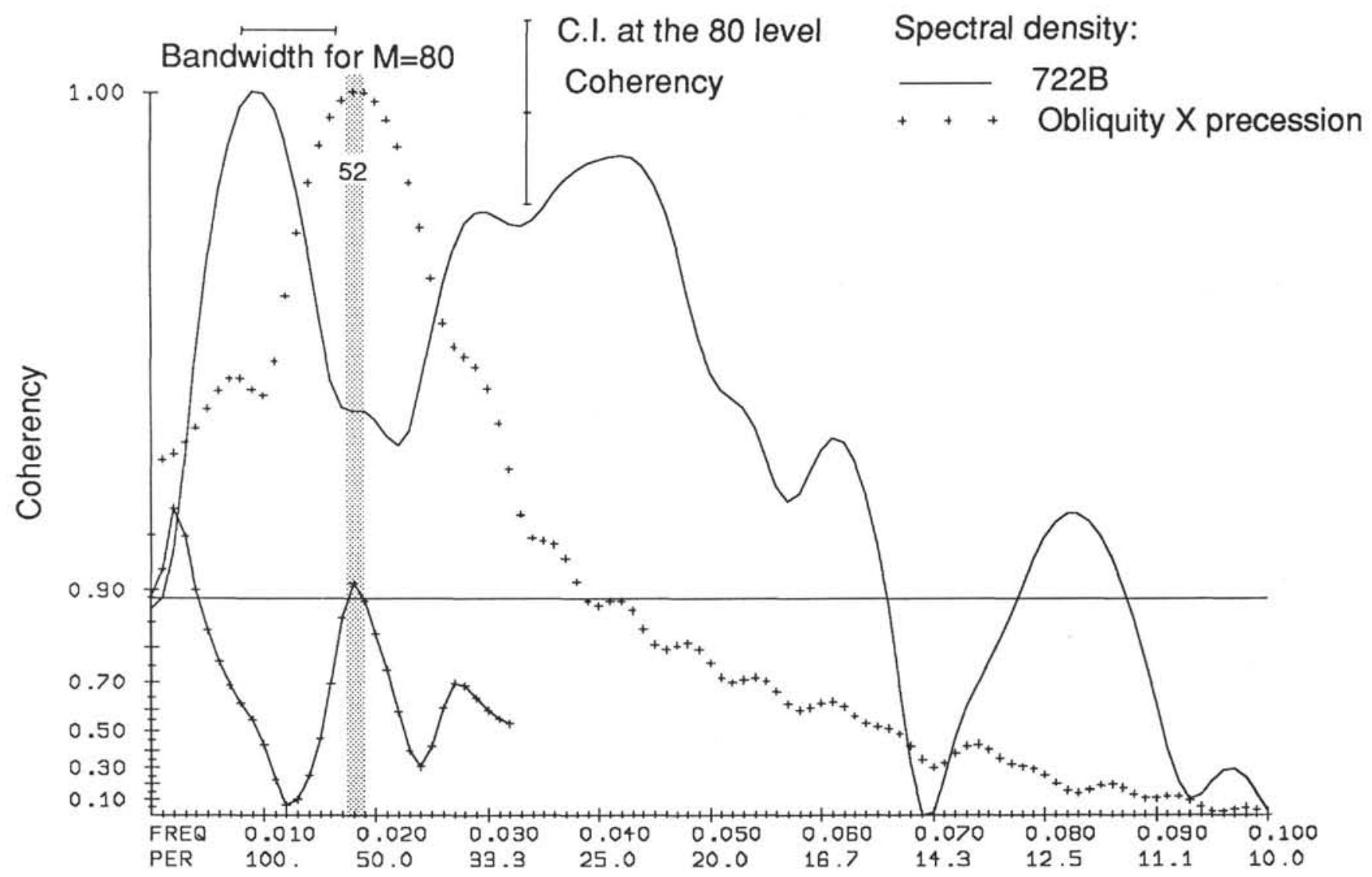

Figure 9. Spectral comparison (see Fig. 6B caption for details of plot) between Hole 722B grain size and the cross-product of precession and obliquity (6-248 k.y.). Significant coherence for the $52 \mathrm{k}$.y. periodicity supports the argument that this cyclicity is a climatically meaningful characteristic of the record and may reflect a nonlinear response of the monsoon to external insolation forcing.

tem. These results provide the basis for a first-order interpretation of the combination frequencies observed in the geological record of monsoon strength.

Based on model results we hypothesize that combination frequencies in the monsoon wind-strength record could be the result of nonlinear interaction between external insolation forcing and an internal climatic feedback mechanism (internal oscillation) produced by an interdependence of snow/ice cover on the Asian Plateau (negative albedo feedback; decreased sensible heating) and the availability of moisture (positive latent heat feedback; increased tropospheric heating). This interaction transfers and amplifies the variability of the internal oscillation (of unknown frequency) to combination frequencies of the external forcing producing the spectrum exhibited by the grain-size record, a mix of primary orbital frequencies and combination frequencies. If the modern interaction between the Indian and $\mathrm{Pa}-$ cific Ocean wind fields can be used as an analogue for past interactions, then we suggest that these same climatic feedbacks may also play a role in producing 29 and $52 \mathrm{k}$.y. periodicities in the Pacific wind records.

\section{SUMMARY}

1. The lithogenic component of sediments from the Owen Ridge provides reliable proxy indicators of dust source-area aridity (lithogenic MAR) and the strength of southwest monsoon winds (lithogenic grain size). The lithogenic MAR indicates enhanced aridity during glacial intervals. The grain-size record is more complex, indicating that summer monsoon wind-strength is strongly influenced by insolation variations due to the Earth's orbital precession, by local and/or global snow/ice-volume changes, and by the availability of latent heat. The interaction of these components yields a record which has no strong relationship to glacial-interglacial cycles.

2. Comparison between the lithogenic percent and grain-size records from Hole 722B and RC27-61 indicates reliable core to core reproducibility. These findings indicate that the eolian signal is regionally strong, coherent, and well preserved despite minor local differences in depositional dynamics.

3. Magnetic susceptibility of sediments from the Owen Ridge is an excellent proxy for lithogenic percent indicating that the ferrimagnetic minerals responsible for the signal are terrestrial in origin and transported to the Owen Ridge via summer winds. Because of the strong positive correlation between magnetic susceptibility and lithogenic percent, the magnetic susceptibility can be cast in terms of lithogenic MAR to produce a very high resolution ( $\sim 1$ k.y.) record of aridity for the Somali and Arabian source-areas.

4. The lithogenic grain-size record shows a distinct decrease in amplitude over the interval 500 k.y.-present compared to the interval 954-500 k.y. This change, however, is not paralleled in the $G$. bulloides upwelling record (Prell, this volume). We are thus left with competing hypotheses to be addressed in future work: (a) the decreased amplitude represents a relatively weaker monsoon and thus a decoupling of the grain size and G. bulloides records over the interval from 500 to 954 k.y., and/or (b) the decrease does not represent weaker monsoon strength but may be related to changes in source-area possibly resulting from the Pliocene-Pleistocene orogeny of the Zagros mountains and the associated development of the modern Persian Gulf. 


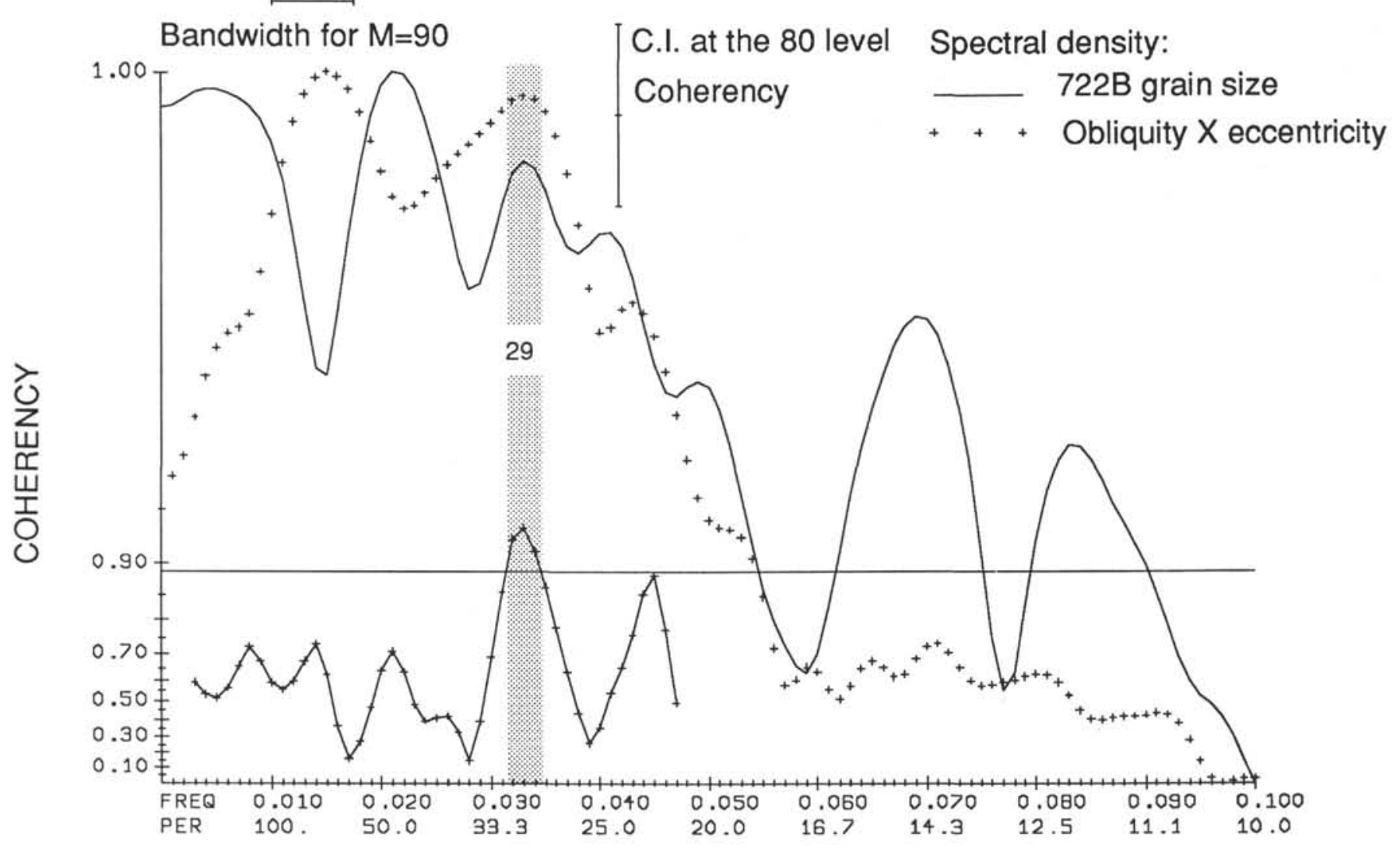

Figure 10. Spectral comparison (see Fig. 6B caption for details of plot) between Hole 722B grain size and the cross-product of eccentricity and obliquity (500-774 k.y.). Significant coherence for the 29 k.y. periodicity supports the argument that this cyclicity is a climatically meaningful characteristic of the record and may reflect a nonlinear response of the monsoon to external insolation forcing.

5. The Hole 722B grain-size record shows significant coherence and zero phase relationships with the RC11-210 grain-size record from the equatorial Pacific for periods at 52 and 29 k.y. These findings indicate a strong positive relationship between the paleo-strength of the Indian Ocean summer monsoon and the Pacific Ocean southeast trades, possibly analogous to modern interannual relationships between the wind fields of these oceans.

6. The 52 and 29 k.y. periodicities in Hole 722B are significantly coherent with the cross-products of eccentricity and obliquity ( 29 k.y.) and precession and obliquity ( $52 \mathrm{k} . \mathrm{y}$.) supporting the argument that these periodicities are real characteristics of the record and may be the result of nonlinear interactions with in the climate system. The broad spectral peak centered on $47.6 \mathrm{k} . \mathrm{y}$. in Hole 722B shows coherence both with the $41 \mathrm{k} . \mathrm{y}$. obliquity cyclicity and with the $52 \mathrm{k}$.y. component of the precession and obliquity cross-product indicating that this variance is related to obliquity but not necessarily in a linear fashion.

7. Climate model results provide a framework for a first-order interpretation of the combination frequencies in the Owen Ridge grain-size record. Combination frequencies could be the result of nonlinear interaction between external insolation forcing and an internal climatic feedback mechanism (internal oscillation) produced by an interdependence of snow/ice cover on the Asian Plateau and the availability moisture from the Indian Ocean.

8. We point out that the coherencies associated with the 52 and 29 k.y. frequencies discussed in this paper are relatively weak, somewhat bandwidth-dependent, and not always associated with clearly resolved spectral peaks. However, we feel justified in presenting them as important features because: (a) inde- pendent records from the Indian and Pacific Oceans are coherent and in phase over these periods; (b) the 29 and 52 k.y. periods are coherent with combination frequencies of the primary Milankovitch bands, providing an external-forcing framework within which to begin interpreting our findings; and (c) there is a modern interannual coupling between the Indian and Pacific Ocean wind fields and SST's (both of which can be monitored in the geological record) possibly providing a modern analogue framework within which we can begin to study the internal mechanisms responsible for the coupling observed in the geological records.

\section{ACKNOWLEDGMENTS}

We are grateful to J. Imbrie, D. Rea, W. Ruddiman, and F. Sirocko for reviews of this manuscript. We also wish to thank S. Carey and J. King for use of the University of Rhode Island Elzone Particle Size Analyzer. This research was supported by National Science Foundation grant OCE84-09478 (Joint Oceanographic Institutions subgrant JSG 87-01) to S. Clemens and W. Prell. This work was performed while S. Clemens held a JOI/USSAC Ocean Drilling Fellowship.

\section{REFERENCES}

Ackerman, S. A., and Cox, S. K., 1982. The Saudi Arabian heat low: aerosol distribution and thermodynamic structure. J. Geophys. Res., 87:8991-9002.

1988. Dust outbreaks associated with the southwest monsoon region. Meteorol. Atmos. Phys., 41:19-34.

Barnett, T. P., 1983. Interaction of the monsoon and Pacific trade wind system at interannual time scales. Part I: the equatorial zone. Mon. Weather Rev., 111:756-773. 
1984a. Interaction of the monsoon and Pacific trade wind system at interannual time scales. Part II: the tropical band. Mon. Weather Rev., 112:2380-2387.

1984b. Interaction of the monsoon and Pacific trade wind system at interannual time scales. Part III: a partial anatomy of the Southern Oscillation. Mon. Weather Rev., 112:2388-2400.

Berger, A., 1984. Accuracy and frequency stability of the Earth's orbital elements during the Quaternary. In Berger, A., Imbrie, J., Hayse, J., Kukla, G., and Saltzman, B. (Eds.), Milankovitch and Climate (Vol. 1): Dordrecht (D. Reidel), 3-39.

Berger, A., and Tricot, C., 1986. Global climatic changes and astronomical theory of paleoclimates. In Cazenave, A. (Ed.), Earth Rotation-Solved and Unsolved Problems: Dordrecht (D. Reidel), 111 129.

Chester, R., Sharples, E. J., and Sanders, G. S., 1985. The concentration of particulate aluminum and clay minerals in aerosols from the northern Arabian Sea. J. Sediment. Petrol., 55:37-41.

Clemens, S. C., and Prell, W. L., 1990. Late Pleistocene variability of Arabian Sea summer monsoon winds and dust source-area aridity: Eolian records from the lithogenic component of deep-sea sediments. Paleoceanography, 5:109-145.

Ghil, M., 1989. Deceptively-simple models of climatic change. In Berger, A., Duplessy, J. C., and Schneider, S. H. (Eds.), Climate and Geosciences: Boston (Kluwer), 211-240.

Grigoryev, A. A., Lipatov, V. B., and Vinogradov, B. V., 1971. Study of the connection between the characteristics of the Earth's surface and some meteorological elements from the global pictures from the automated inter-planetary station Zond 7. Adv. Space Res., 11:727730.

Hovan, S. A., Rea, D. K., Pisias, N. G., and Shackleton, N. J., 1989. A direct link between the China loess and marine $\delta^{18} \mathrm{O}$ records: aeolian flux to the north Pacific. Nature, 340:296-298.

Imbrie, J., Hays, J. D., Martinson, D. G., McIntyre, A., Mix, A. C., Morley, J. J., Pisias, N. G., Prell, W. L., and Shackleton, N. J., 1984. The orbital theory of Pleistocene climate: support from a revised chronology of the marine delta $\delta^{18} \mathrm{O}$ record. In Berger, A., Imbrie, J., Hays, J., Kukla, G., and Salzman, B. (Eds.), Milankovitch and Climate (Vol. 1): Dordrecht (Reidel), 269-305.

Imbrie, J., McIntyre, A., and Mix, A., 1989. Oceanic response to orbital forcing in the Late Quaternary: observational and experimental strategies. In Duplessy, J. C., et al. (Eds.), Climate and Geosciences: Boston (Kluwer), 105-120.

Jenkins, G. M., and Watts, D. G., 1968. Spectral Analysis and Its Applications: Oakland (Holden Day).

Kassler, P., 1973. The structural and geomorphic evolution of the Persian Gulf. In Purser, B. H. (Ed.), The Persian Gulf: New York (SpringerVerlag), 11-32.

Kukla, G., 1987. Loess stratigraphy in central China. Quat. Sci. Rev., 6: 191-219.

Kukla, G., Heller, F., Ming, L. X., Chun, X. T., Sheng, L. T., and Sheng, A. Z., 1988. Pleistocene climates in China dated by magnetic susceptibility. Geology, 16:811-814.

Kutzbach, J. E., 1981. Monsoon climate of the Early Holocene: climate experiment with the Earth's orbital parameters for 9000 years ago. Science, 214:59-61.

Kutzbach, J. E., and Otto-Bliesner, B. L., 1982. The sensitivity of the African-Asian monsoonal climate to orbital parameter changes for 9000 years B.P. in a low-resolution General Circulation Model. J. Atmos. Sci., 39:1177-1188.

Le Treut, H., Portes, J., Jouzel, J., and Ghil, M., 1988. Isotopic modeling of climatic oscillations: implications for a comparative study of marine and ice core records. J. Geophys. Res., 93:9365-9383.

McDonald, W. F., 1938. Atlas of Climatic Charts of the Oceans: Washington, D.C. (U.S.D.A., Weather Bur.), charts 59-62.

Middleton, N. J., 1986. Dust storms in the Middle East. J. Arid Environ., 10:83-96.

Milliman, J. D., Quraishee, G. S., and Beg, M.A.A., 1984. Sediment discharge from the Indus River to the ocean: past, present and fu- ture, In Haq, B. U., and Milliman, J. D. (Eds.), Marine Geology and Oceanography of Arabian Sea and Coastal Pakistan: New York (Van Nostrand Reinhold), 65-70.

Murray, D. W., Pisias, N. G., Lyle, M. W., Heath, G. R., and Dimond, $\mathrm{J}$., in prep. Biogenic and non-biogenic sediment accumulation in the central equatorial Pacific during the last 250,000 years.

Nair, R. R., Ittekkot, V., Manganini, S. J., Ramaswamy, V., Haake, B., Degens, E. T., Desai, B. N., and Honjo, S., 1989. Increased particle flux to the deep ocean related to monsoons. Nature, 338:749-751.

Pestiaux, P., and Berger, A., 1984. An optimal approach to the spectral characteristics of deep-sea climatic records. In Berger, A., Imbrie, J., Hays, J., Kukla, G., and Saltzman, B. (Eds.), Milankovitch and Climate (Vol. 1): Dordrecht (D. Reidel), 417-445.

Pestiaux, P., Van Der Mersch, I., Berger, A., and Duplessy, J. C., 1988. Paleoclimatic variability at frequencies ranging from 1 cycle per 10,000 years to 1 cycle per 1000 years: evidence for nonlinear behaviour of the climate system. Clim. Change, 12:9-37.

Pisias, N. G., and Rea, D. K., 1988. Late Pleistocene paleoclimatology of the central equatorial Pacific: sea surface response to the southeast Trade Winds. Paleoceanography, 3:21-37.

Prodi, F., Santachiara, G., and Oliosi, F., 1983. Characterization of aerosols in marine environments (Mediterranean, Red Sea, and Indian Ocean). J. Geophys. Res., 88:10957-10968.

Prospero, J. M., 1981. Arid regions as sources of mineral aerosols in the marine atmosphere. In Péwé, T. L. (Ed.), Desert Dust-Origin, Characteristics, and Effects on Man: Spec. Pap.-Geol. Soc. Am., 186: 71-86.

Pye, K., 1987. Aeolian Dust and Dust Deposits: New York (Academic Press), 97-98.

Ruddiman, W. F., Raymo, M. E., Martinson, D. G., Clement, B. M., and Backman, J., 1989. Pleistocene evolution: northern hemisphere ice sheets and north Atlantic Ocean. Paleoceanography, 4:353-412.

Saltzman, B., Hansen, A. R., and Maasch, K. A., 1984. The Late Quaternary glaciation as the response of a three-component feedback system to Earth-orbital forcing. J. Atmos. Sci., 41:3380-3389.

Savoie, D. L., Prospero, J. M., and Nees, R. T., 1987. Nitrate, non-seasalt sulfate, and mineral aerosol over the northwestern Indian Ocean. J. Geophys. Res., 92:933-942.

Shipboard Scientific Party, 1989. Site 722. In Prell, W. L., Niitsuma, N., et al., Proc. ODP, Init. Repts., 117: College Station, TX (Ocean Drilling Program), 255-318.

Sirocko, F., and Sarnthein, M., 1989. Wind-borne deposits in the northwest Indian Ocean: record of Holocene sediments versus modern satellite data. In Leinen, M., and Sarnthein, M. (Eds.), Paleoclimatology and Paleometeorology-Modern and Past Patterns of Global Atmospheric Transport. NATO ASI Ser., 282:401-433.

Street-Perrott, F. A., and Harrison, S. P., 1985. Lake levels and climate reconstruction. In Hecht, A. D. (Ed.), Paleoclimate Analysis and Modeling: New York (Wiley), 291-340.

Street, A. F., and Grove, A. T., 1979. Global maps of lake-level fluctuations since 30,000 yr B.P. Quat. Res., 12:83-118.

Thompson, R., and Oldfield, F., 1986. Environmental Magnetism: Boston (Allen and Unwin), 21-38; 141-152.

Tsoar, H., and Pye, K., 1987. Dust transport and the question of desert loess formation. Sedimentology, 34:139-153.

Van Campo, E., Duplessy, J. C., and Rossignol-Strict, M., 1982. Climatic conditions deduced from a 150-kyr oxygen isotope-pollen record from the Arabian Sea. Nature, 296:56-59.

Webster, P. J., 1987. The elementary monsoon. In Fein, J. S., and Stephens, P. L. (Eds.), Monsoons: New York (Wiley), 3-32.

Date of initial receipt: 1 September 1989

Date of acceptance: 29 January 1990

Ms 117B-138 